\title{
Hippocampal cannabinoid 1 receptors are modulated following cocaine self- administration in male rats
}

David de Sa Nogueira ${ }^{1,4}$, Romain Bourdy ${ }^{1}$, Rafael Alcala-Vida ${ }^{1}$, Dominique Filliol ${ }^{1}$, Virginie Andry $^{2}$, Yannick Goumon ${ }^{2}$, Jean Zwiller ${ }^{1}$, Pascal Romieu ${ }^{1}$, Karine Merienne ${ }^{1}$, Mary C. Olmstead $^{3}$, Katia Befort $^{1 *}$

\section{Running title: Cocaine transcriptional and epigenetic regulations of the endocannabinoid system}

${ }^{1}$ Université de Strasbourg, Laboratoire de Neurosciences Cognitives et Adaptatives (LNCA), Centre de la Recherche Nationale Scientifique, 12 rue Goethe, F-67000, Strasbourg France ${ }^{2}$ Institut des Neurosciences Cellulaires et Intégratives (INCI), UPR 3212, CNRS, 8 Allée du Général Rouvillois, 67000, Strasbourg, France

${ }^{3}$ Department of Psychology, Center for Neuroscience Studies, Queen's University, Kingston, Ontario K7L 3N6, Canada

${ }^{4}$ Current address: Brain Health Institute, Rutgers University and Rutgers Biomedical and Health Sciences, 683 Hoes Lane West, 08854, Piscataway, New Jersey, USA

\section{*Correspondance}

Katia Befort

Laboratoire de Neurosciences Cognitives et Adaptatives LNCA

Université de Strasbourg Faculté de Psychologie,

12 rue Goethe, F-67000

Strasbourg, France

E-mail: katia.befort@unistra.fr

Key words: cannabinoid, gene expression, reward, addiction, epigenetic

\section{Abbreviations:}

Amy: amygdala; Cocaine-SA: cocaine self-administration; DS: dorsal striatum; GPCR: G protein coupled receptor; HPC: hippocampus; PFC: prefrontal cortex; NAc: nucleus accumbens; VTA: ventral tegmental area.

\section{Words}

Abstract : 249

Introduction : 1056

Discussion : 1548 


\begin{abstract}
Cocaine addiction is a complex pathology inducing long-term neuroplastic changes that, in. turn, contribute to maladaptive behaviors. This behavioral dysregulation is associated with transcriptional reprogramming in brain reward circuitry, although the mechanisms underlying this modulation remain poorly understood. The endogenous cannabinoid system may play a role in this process in that cannabinoid mechanisms modulate drug reward and contribute to cocaine-induced neural adaptations. In this study, we investigated whether cocaine selfadministration induces long-term adaptations, including transcriptional modifications and associated epigenetic processes. We first examined endocannabinoid gene expression in reward-related brain regions of the rat following self-administered $(0.33 \mathrm{mg} / \mathrm{kg}$ intravenous, FR1, 10 days) cocaine injections. Interestingly, we found increased Cnrl expression in several structures, including prefrontal cortex, nucleus accumbens, dorsal striatum, hippocampus, habenula, amygdala, lateral hypothalamus, ventral tegmental area and rostromedial tegmental nucleus, with most pronounced effects in the hippocampus. Endocannabinoid levels, measured by mass spectrometry, were also altered in this structure. Chromatin immunoprecipitation followed by qPCR in the hippocampus revealed that two activating histone marks, $\mathrm{H} 3 \mathrm{~K} 4 \mathrm{Me} 3$ and $\mathrm{H} 3 \mathrm{~K} 27 \mathrm{Ac}$, were enriched at specific endocannabinoid genes following cocaine intake. Targeting CB1 receptors using chromosome conformation capture, we highlighted spatial chromatin re-organization in the hippocampus, as well as in the nucleus accumbens, suggesting that destabilization of the chromatin may contribute to neuronal responses to cocaine. Overall, our results highlight a key role for the hippocampus in cocaine-induced plasticity and broaden the understanding of neuronal alterations associated with endocannabinoid signaling. The latter suggests that epigenetic modifications contribute to maladaptive behaviors associated with chronic drug use.
\end{abstract}




\section{Introduction}

Substance use disorders (SUD), characterized by compulsive drug-seeking, craving, and a high probability of relapse, remain one of the most pressing health issues facing industrialized countries. In addition to dramatic effects on personal and public well-being, the economic costs of SUDs are enormous, totaling more than $\$ 700$ billion in the USA [1], $£ 40$ billion in the UK [2], and $€ 65.7$ billion in Europe [3]. Cocaine is the second most-commonly consumed illicit drug after cannabis: approximately $1.3 \%$ of Europeans used the drug within the last year, with inter-country prevalence rates ranging from $0.2 \%$ to $4.6 \%$ in young adults [4]. Rates of cocaine abuse rose continuously over the last decade, driven by increased drug purity as well as increased rates of world production. Concurrent use of other psychoactive substances exacerbated the detrimental health effects of cocaine, leading to an increased demand for addiction treatment. In addition, excessive cocaine use is directly linked to several negative outcomes, including cardiac complications [5] and long-term cognitive deficits [6]. Like many SUDs, treatment options for cocaine abuse are limited and minimally effective, partly because the probability of relapse remains high even after prolonged periods of abstinence [7].

The persistence of behavioral and affective changes in cocaine addiction likely reflects long-term adaptations in neural systems that support continued drug use [7]. These may include alterations in brain connectivity [8], signaling [9], neuronal plasticity [10], or neurotransmitter and neuromodulator dynamics [11-13]. The molecular mechanisms underlying these adaptive responses to repeated drug exposure are poorly characterized, but appear to involve transcriptional adaptations $[14,15]$. Recent evidence has highlighted the role of epigenetic processes in controlling chromatin access and regulating gene expression following long-term exposure to drugs of abuse, thereby contributing to the persistent dysfunction of neuronal circuits associated with addiction [16-19].

The long-term impact of chronic cocaine use on molecular mechanisms involves adaptations in the endocannabinoid system, which plays a key role in reward and motivation [20-22]. For example, the endocannabinoids, anandamide (AEA) and 2-arachidonoylglycerol (2-AG), modulate drug reward via an action at brain cannabinoid receptors (CB1Rs and CB2Rs). CB1Rs are highly expressed in both GABAergic and glutamatergic neurons [23], as well as in astrocytes [24]. CB2Rs, first described as a peripheral receptor, have been identified, more recently, in the hippocampus (HPC), striatum and thalamus [25-27], and on the soma of dopaminergic neurons in the ventral tegmental area (VTA) [28]. This system is 
regulated by intracellular proteins that mediate responses via the C-terminal and other intracellular receptor domains. Among these, the cannabinoid receptor interacting protein (Crip1A) modulates CB1R signaling and its endocytosis through specific intracellular interactions (for reviews, see [29, 30]. Metabolizing enzymes for synthesis (NAPE$\mathrm{PLD} / \mathrm{DAGL} \alpha$ ) or degradation (FAAH/ MAGL) of AEA and 2-AG are also modulators of the endocannabinoid system [31].

Preclinical studies confirm a contribution of endocannabinoid system function to cocaine-induced reward. For example, the CB1R agonist, HU210, promotes the reinstatement of cocaine-seeking whereas a selective CB1R antagonist, SR141716 (Rimonabant), dosedependently decreases this behavior [32]. Mice deficient for CB1Rs are less prone to selfadminister cocaine [33] and show altered behavioral responses to other cocaine effects [34]. Moreover, in conditional knock out animals where CB1Rs were deleted in selected neuronal populations, CB1Rs expressed in GABA neurons regulate sensitivity to cocaine, whereas those expressed in glutamatergic neurons modulate associative learning processes [35]. CB2Rs also play a role in cocaine-induced responses as intra-NAc or intra-VTA activation of this receptor, using the agonist JWH133, diminished cocaine self-administration (cocaine-SA) and cocaine-induced increases in extracellular dopamine (DA); the selective CB2R antagonist, AM630, prevented these effects [28, 36, 37].

Pharmacological inhibition of endocannabinoid lipid degradation provides another tool to investigate the impact of endocannabinoid tone on behavioral responses to cocaine (see details in [38]). For example, cocaine-induced behavioral sensitization in mice, paralleled by a large stimulation of extracellular DA levels in the NAc, was blocked by Rimonabant pretreatment and facilitated by inhibiting the FAAH enzyme. These results suggest that an increase in endocannabinoid tone could be involved in neuroadaptations induced by cocaine [39]. In contrast, the FAAH inhibitor, URB597, did not modify cocaine-SA in monkeys [40] or rodents [41], whereas it reduced cocaine- and cue-induced reinstatement of cocaineseeking in rats. Other studies reported no change in cocaine-induced hyperlocomotion following selective inhibition of AEA and 2-AG (URB597 and JZL184, respectively) [42]. In sum, these studies provide further support for endocannabinoid system involvement in cocaine-induced effects, although seemingly contradictory findings were reported with different behavioral measures.

Cocaine may produce its behavioral effects by modulating endocannabinoid system gene or protein expression, or by altering endocannabinoid levels in specific brain structures. 
In support of this idea, cocaine-SA in mice increased $\mathrm{Cnrl}$ expression in the prefrontal cortex (PFC) and HPC [43, 44] with no effects in the cerebellum [45]. The effects of cocaine-SA on CB1R immunoreactivity are more contradictory, causing both increases [46] and decreases [47] in hippocampal regions. Endocannabinoid levels, not modified in a cocaine-induced hyperlocomotion paradigm [42], also appear to vary following cocaine administration with decreased 2-AG levels and no change in AEA levels in the limbic forebrain following chronic, passive injections [48]. Voluntary intake paradigms (i.e., cocaine-SA) have also produced a range of effects on brain endocannabinoid levels. These include no changes in the NAc shell [49], increased 2-AG levels in the frontal cortex and cerebellum, decreased 2-AG levels in the HPC and striatum, and decreased AEA levels in the cerebellum [50]. Overall, chronic cocaine clearly modulates endocannabinoid system processes in several brain structures, but there is little consistency in the reported results across studies.

The aim of this study was to investigate, in more detail, the relationship between endocannabinoid system function and cocaine intake. First, we examined whether selfadministered cocaine regulated cannabinoid receptor $(\mathrm{CB} 1 \mathrm{R}, \mathrm{CB} 2 \mathrm{R})$ function by measuring gene expression of both receptors. We also assessed the Crip1A and enzyme transcripts for endocannabinoid synthesis (NAPE-PLD/DAGL $\alpha$ ) as well as degradation (FAAH/ MAGL). We examined classical brain regions associated with cocaine-induced reward, specifically the NAc, DS, and PFC. We included the HPC, as both CBRs are expressed in this brain structure, with a high level of CB1Rs, and the region may play a unique role in drug-associated memories. We also measured endocannabinoid levels (2-AG and AEA) in targeted sites, and investigated whether CB1R expression or functionality was altered. Finally, we extended this study by testing whether epigenetic adaptations or chromatin conformation looping occurred at Dagl $\alpha$ and Faah, or Cnrl genes following cocaine intake. 


\section{Materials and Methods}

\subsection{Subjects}

Male Wistar rats (Janvier Laboratories, France), weighing $175 \mathrm{~g}$ at arrival, were group housed for two weeks, in standard cages, in a temperature and humidity-controlled environment with ad libitum access to food and water. Rats $(n=58)$ were housed under a reversed $12 \mathrm{~h}$ light/dark cycle (lights OFF at 7:00 AM). Animals were single-housed following surgery and for the remainder of the experiment. All efforts were made to minimize animal suffering and to reduce the number of animals. Procedures and animal care were performed according to the European Union laws for animal studies and approved by the local ethics committee (CREMEAS) and the French Research Ministry (APAFIS\#2015012716049550). A timeline displaying the sequence of experimental procedures is shown in Supplemental Figure 1.

\subsection{Cocaine self-administration}

An intravenous catheterization procedure was performed as previously described [51]. Briefly, rats were anesthetized $(1 \mathrm{ml} / \mathrm{kg}$; ketamine -Imalgene $1000 \AA, 90 \mathrm{mg} / \mathrm{kg}$, and xylazine -Rompun ${ }^{\circledR}, 10 \mathrm{mg} / \mathrm{kg}$; Centravet, France) prior to surgical implantation of an indwelling catheter in the right jugular vein. Catheters were flushed daily with $150 \mu$ saline solution containing $100 \mathrm{U} / \mathrm{ml}$ heparin and $50 \mathrm{mg} / \mathrm{ml}$ ampicillin to prevent clotting and infection, respectively. Cocaine-SA training started following a 7-day recovery period.

Self-administration was performed in dark operant chambers $(30 \times 30 \times 30 \mathrm{~cm})$ located in a sound-attenuated room. A computer driven syringe pump (Imetronic, Pessac, France) activated a $10 \mathrm{ml}$ syringe and pushed fluid into Silastic ${ }^{\circ}$ tubing connected to the rat. Each chamber was equipped with two $2 \mathrm{~cm}$-diameter holes, $4 \mathrm{~cm}$ above the floor. Holes were selected as active for delivering cocaine or inactive (without programmed consequence) and nose-pokes into both holes were recorded. One nose-poke into the active hole (fixed ratio, FR1) triggered the intravenous (i.v.) delivery of a $0.33 \mathrm{mg} / \mathrm{kg}$ dose of cocaine hydrochloride (60 $\mu \mathrm{l}$ in $2 \mathrm{~s})$ in the cocaine-SA group $(n=30)$, or of the same volume of saline $(\mathrm{NaCl} 0.9 \%)$ in Saline-SA control animals $(n=28)$, which were run concurrently. A 40 s-time-out period began simultaneous to the cocaine infusion. No cut-off was applied for the number of selfinfusions during the session. This FR1 experiment was conducted over 10 days, with daily $2 \mathrm{~h}$ sessions. 


\subsection{Brain dissection}

Twenty-four hours following the last SA session, rats were given an overdose of pentobarbital (100 mg/kg i.v.) followed by decapitation to perform brain extraction. Brains were cut in 1-mm thick slices using a coronal brain matrix chilled on ice (Harvard apparatus, Holliston, MA, USA). Structures of interest were collected according to the rat brain stereotaxic atlas [52], with details provided in Supplemental Table 1. Samples were immediately frozen on dry ice and kept at $-80^{\circ} \mathrm{C}$. Extractions were processed in less than 20 min to avoid alterations in levels of AEA, which increase rapidly postmortem [53].

\subsection{Molecular and biochemical analysis}

\subsubsection{Quantitative real-time PCR}

RNA was extracted from all regions of interest, as previously described $[54,55]$. Total RNA was extracted (Ribozol, VWR, Fontenay-sous-bois, France) and further processed (750 ng) to obtain cDNA (iScript ${ }^{\mathrm{TM}}$ cDNA Synthesis Kit, Biorad, France). Real-time PCR was performed in triplicate using a CFX96 Touch $^{\mathrm{TM}}$ apparatus and Sso Advanced ${ }^{\mathrm{TM}}$ Universal $^{\mathrm{T}}$ SYBR Green supermix (Biorad, France). Thermal cycling parameters were $30 \mathrm{~s}$ at $95^{\circ} \mathrm{C}$ followed by 40 amplification cycles of $5 \mathrm{~s}$ at $95^{\circ} \mathrm{C}$ and $45 \mathrm{~s}$ at $60^{\circ} \mathrm{C}$. Primer sequences for all tested genes are given in Supplemental Table 2. Expression levels were normalized to RplpO (Ribosomal Protein Lateral Stalk Subunit P0) housekeeping gene levels [56] and compared between control (saline) and treated (cocaine) samples using the 2- $\Delta \Delta \mathrm{Ct}$ method [57].

\subsubsection{Mass spectrometry}

PFC, HPC, NAc and DS samples (n=7-8/group) were processed as previously detailed $[54,55]$. Briefly, samples were sonicated, centrifuged and the supernatant $(150 \mu 1)$ was mixed with $50 \mu \mathrm{l}$ of acetonitrile (ACN) 100\% containing 400.26 pmol of D8-2AG (ref sc-480539; Santa Cruz, Heidelberg, Germany) and 100.15 pmol of D4-AEA (Tocris/Biotechne, Lille, France). Following centrifugation, supernatants were collected and evaporated to dryness. Samples were re-suspended in $20 \mu \mathrm{l}$ of $\mathrm{ACN} 30 \% / \mathrm{H}_{2} \mathrm{O} 69.9 \%$ / formic acid $0.1 \%$ (v/v/v) and loaded onto a microbore C18 ODS column (1x100 mm, $3 \mu \mathrm{m}$ UniJet microbore ODS, ref MF8949, BioAnalytical Systems Inc., West Lafayette, U.S.A.) heated at $40^{\circ}$ C. Elution was performed at a flow rate of $50 \mu \mathrm{l} / \mathrm{min}$ by applying a gradient of mobile phases $\mathrm{A} / \mathrm{B}$. Electrospray ionization was achieved in the positive mode using nitrogen and is detailed in Supplemental Table 3. Identification of the compounds was based on precursor ions, selective fragment ions, and retention times obtained for 2-AG, AEA, D8-2-AG and D5-AEA. Qualification and quantification were performed in multiple reaction monitoring mode and 
quantification was obtained using Quan Browser software (Thermo Scientific). The amount of 2-AG (nmol) and AEA (pmol) were normalized according to protein levels (mg).

\subsubsection{Agonist-stimulated $\left[{ }^{35} S\right]-G T P \gamma S$ binding assay}

PFC ( $n=4-9 /$ group), DS ( $n=4-9 /$ group), and HPC samples ( $n=7 /$ group) were processed using a $\left[{ }^{35} \mathrm{~S}\right]-\mathrm{GTP} \gamma \mathrm{S}$ binding assay to measure $\mathrm{G}$ protein activation following CB1R stimulation. Not enough material was available from NAc samples to perform this experiment. Samples were homogenized in sucrose $0.25 \mathrm{M}$, centrifuged at $1100 \mathrm{~g}\left(4^{\circ} \mathrm{C}, 10\right.$ min), and supernatants collected for centrifugation $\left(30,000 \mathrm{~g}, 4^{\circ} \mathrm{C}, 30 \mathrm{~min}\right)$. Pellets were then homogenized in sucrose $0.32 \mathrm{M}$, subjected to Bradford analysis for total protein concentration, and then stored at $-80^{\circ} \mathrm{C}$. Arachidonyl-2'-chloroethylamide (ACEA), a potent and highly selective CB1R agonist [58], was used in this assay to activate the receptor at different doses. Proteins $(50 \mu \mathrm{g})$ were incubated in the assay buffer $(50 \mathrm{mM}$ Tris- $\mathrm{HCl} \mathrm{pH} 7.4 ; 3 \mathrm{mM} \mathrm{MgCl} 2$; 0.2mM EGTA; 100mM NaCl) containing 0.1nM [ $\left.{ }^{35} \mathrm{~S}\right]-G T P \gamma \mathrm{S}$ (NEG030H, PerkinElmer, Courtaboeuf, France), $30 \mu \mathrm{M}$ GDP and ACEA $\left(10^{-10} \mathrm{M}\right.$ to $\left.10^{-5} \mathrm{M}\right)$ for $1 \mathrm{~h}$ at $25^{\circ} \mathrm{C}$. Binding was performed in triplicate in 96 deep-well plates. Radioactivity was detected on a Top-Count scintillation counter (PerkinElmer, Billerica, MA, USA). Basal $\left[{ }^{35} \mathrm{~S}\right]-\mathrm{GTP} \gamma \mathrm{S}$ binding was determined in the absence of agonist, and non-specific binding was assessed by replacing $\left[{ }^{35} \mathrm{~S}\right]-\mathrm{GTP} \gamma \mathrm{S}$ with $10 \mu \mathrm{M}$ of non-radiolabeled GTP $\gamma \mathrm{S}$. Stimulated specific binding was converted to percentage of basal specific binding, defined as 100\%. Stimulation (\%) EC50s and IC50s were calculated for each sample and averaged.

\subsubsection{Western blot analysis}

Proteins ( $20 \mu \mathrm{g}, \mathrm{n}=4-5 / \mathrm{group})$ were separated on a stain free polyacrylamide gel 415\% (Biorad, France) and transferred to polyvinylidene difluoride membranes (Biorad, France), which were blocked in PBS-I-block (Tropix, Applied Biosystems) in 0.1\% Tween 20 buffer for $1 \mathrm{~h}$. Blots were further incubated overnight at $4{ }^{\circ} \mathrm{C}$ in an anti-CB1R antibody (1:2000; \#10006590; Cayman), prior to incubation with biotinylated secondary goat anti-body (1:50 000; Jackson ImmunoResearch Laboratories, Inc) for $1 \mathrm{~h}$ at room temperature. A pilot control blotting experiment using this antibody on brain samples prepared from mice deficient for the CB1Rs (kind gift from Dr C Nozaki) confirmed the absence of a stained band (53kDA) in our conditions (Supplemental Figure 4B). Antibody binding was revealed by chemiluminescence (ECL Prime, GE healthcare, Piscataway, NJ, USA), detected using the ChemiDoc Imager (Biorad, France). Bands were quantified as mean optical intensity and normalization was performed using stain free (total protein), as previously described [59]. 


\subsection{Epigenetic analysis}

\subsubsection{Chromatin immunoprecipitation}

Samples ( $n=5-7 /$ group) were prepared as previously described [51] with minor modifications. Briefly, frozen tissues were ground on carbonic ice before fixation (1\% formaldehyde) and quenched with glycine $(0.125 \mathrm{M})$. Tissue fragments were washed in the presence of protease inhibitors (\#4693132001, Roche, France); homogenized and lysates were sheered (DNA fragments $<600 \mathrm{bp}$ ). Protein A magnetic beads (Dynabeads, Invitrogen) were coated overnight with the respective antibody of interest (H3K4Me3, \#ab8580; H3K27Ac, \#ab4729, Abcam, France), washed and added to sheared chromatin for histone ChIP. A sample of each sheared chromatin (10\%) was used as input control. Samples were washed and reverse cross-linking was performed at $65^{\circ} \mathrm{C}$ overnight, and DNA purified (DNA mini elute kit, Qiagen, France). Additionally, a negative control without IgG was performed to test for nonspecific binding [51]. The \% of enrichment was calculated as follow: (signal H3K27ac signal no ab)/Input *100. PCR at genomic and exon regions for Cnr1, Dagla and Faah associated with the immunoprecipitated proteins were performed (primers listed in

\section{Supplemental Table 2).}

\subsubsection{Circularized chromosome-conformation capture (4C)}

To investigate the potential occurrence of spatial reorganization of the chromatin following cocaine intake, a circular chromatin conformation capture (4C-seq) experiment was performed once on pooled samples from two rats, as previously described with minor modifications [60]. Briefly, pooled samples of the NAc or HPC (2 rats/group) were homogenized in ice-cold PBS supplemented with 1x Protease Inhibitors Cocktail (PIC, cOmplete EDTA free, Roche) and cross-linked with $2 \%$ formaldehyde. Nuclei were extracted following a classical hypotonic shock protocol. Purified nuclei (5 million nuclei per biological condition) were processed for 4C-seq template generation using DpnII and Csp6I as first and second restriction enzymes, respectively. The resultant 4C DNA template was used to generate 4C-seq libraries by inverse PCR (Long Template PCR system, Roche) using targetspecific designed primers containing Illumina sequencer adapters (Supplemental Table 2). For primer design, a region surrounding the TSS of the Cnrl gene (+/- $2 \mathrm{~kb})$ was selected. Finally, generated libraries were purified with SPRI select beads (Beckman, USA), quantified using Bioanalyzer, and pooled equimolarly for sequencing using 50bp single-end Hiseq 4000 sequencer (IGBMC Genomeast platform; http://genomeast.igbmc.fr).

The analysis was performed using a custom perl script based on previous analysis [61]. Reads were de-multiplexed in individual fastq files using sabre tool 
(https://github.com/najoshi/sabre, version 1.0) according to the reading primer of each bait. Fastq reads were then filtered and mapped to the rat Rn6 genome using Bowtie [62]. Mapped regions were assigned to a fragment-end coordinate generated by the in-silico digestion of the reference genome using the primary and secondary restriction enzymes recognition sequences (DpnII and Csp6I respectively). To allow for data comparison between saline-SA and cocaine-SA groups or between the two structures, quantile normalization was performed using 4See R package [63] and resulting bedGraphs were observed using pyGenomeTracks [64]. H3K27ac data were obtained from GSM2520838 and re-aligned to the rat Rn6 genome. Significant interactions were called on individual datasets using peakC ${ }^{86}$ with default parameters, including a window size of 15 fragments. To assess the overlap between detected intersections for each bait in the different biological conditions, we used bedsect multiple intersection tool and calculated the coverage in nucleotides of the different intersecting and non-intersecting regions to generate Chow-Ruskey area-proportional plots using Intervene [65].

\subsection{Statistical analysis}

All results are expressed as mean \pm SEM. Data from qPCR were analyzed using unpaired student's $t$-test. Separate analyses were conducted in each brain structure. Correlations were performed to compare total cocaine intake with endocannabinoid levels, gene expression or Emax values, when possible (limited number of animals performed several analysis). Behavioral data were analyzed using repeated measures ANOVAs with group as between-subject factor and session as a repeated factor. The ANOVAs were followed by a Tukey's post hoc test when required for multiple comparisons. Significance was set at $p \leq$ 0.05 (GraphPad V.7).

\section{Results}

\subsection{Transcriptional changes in the endocannabinoid system following cocaine self- administration}

The number of cocaine injections was stable across the 10 cocaine-SA sessions and significantly higher than the number of saline infusions across all sessions, $F(1,56)=334.9, p$ $<.0001$ (Figure 1A). The ANOVA analysis for the number of nose pokes revealed a group effect $(\mathrm{F}(3,112)=31.4, \mathrm{p}<.0001)$. The animals receiving cocaine completed more than $80 \%$ of nose pokes in the active hole starting at session 5, with the post-hoc analysis indicating a 
significant difference between active and inactive nosepokes for sessions 5 to 9 ( $p<.0003$ ). (Figure 1B). Over the 10 sessions, rats in the cocaine-SA group received an average of $32 \pm$ $0.5 \mathrm{mg} / \mathrm{kg}$ of cocaine per day. In order to examine gene expression changes in this condition, we performed qPCR analysis in several brain structures. As shown in Figure 1C, cocaine-SA altered gene expression of both CBRs in a number of brain regions, although the effects were often in opposite directions. More specifically, $\mathrm{Cnrl}$ expression was significantly increased in the NAc, $t(16)=3.688, p=.002, \mathrm{DS}, t(17)=3.062, p=.007$, and the HPC, $t(14)=5.289, p<$ .001 , whereas Cnr2 expression was significantly decreased in the PFC, $t(12)=2.668, p=$ $.020, \mathrm{DS}, t(16)=3.963, p=.001$, and LH, $t(9)=3.569, p=.006($ Figure 1C and

Supplemental Figure 2). No correlation was observed between $\mathrm{Cnrl}$ expression and total cocaine intake (Supplemental Figure 3). There were no significant differences between saline-SA and cocaine-SA groups in CBR gene expression in other brain regions, and no group differences in the regulation of CriplA in the PFC, NAc, DS or HPC.

Changes in gene expression of endocannabinoid enzymes (Figure 1D) were observed in the NAc, following cocaine-SA, with an increase (Napepld: $t(19)=3.043, p=.007$ ) and decrease $[$ Faah, $t(16)=2.229, p=.041)$ in the expression of genes related to synthesis and degradation, respectively. Cocaine-SA also increased Faah expression in the PFC, $t(13)=$ $2.196, p=.046$, with no other changes observed in this brain region (all $p \mathrm{~s}>.05$ ). The most dramatic and consistent changes in gene expression were observed in the HPC, with increases in enzymes related to synthesis [Nape-pld: $t(13)=2.737, p=.017 ;$ Dagl $\alpha: t(12)=12.540, p<$ .001 ] as well as degradation [Faah: $t(12)=10.190, p<.001 ;$ Mgll: $t(12)=2.275, p=.042]$. Minimal changes were observed for these transcripts in the other brain structures, Hab, Amy, LH, VTA and RMTg (Supplemental Figure 2).

\subsection{Modulation of endocannabinoid levels following cocaine self-administration}

To determine endocannabinoid content in the PFC, NAc, DS and HPC, we performed mass spectrometry. Measures of AEA and 2-AG levels revealed similar levels to those previously reported [66], with a higher proportion of both eCBs in the HPC and a lower proportion in the NAc (Figure 2A). In addition, AEA levels were decreased in the NAc, $t(14)$ $=2.159, p=.048$, and DS, $t(14)=2.449, p=.028$, but increased in the HPC, $t(13)=2.647, p$ $=.020$, and unchanged in the PFC, $t(14)=1.372, p=.191$, following cocaine-SA (Figure 2B). An increase of 2-AG levels was detected in the NAc, $t(14)=3.666, p=.003$, and HPC, $t(13)=2.377, p=.033$, whereas no detectable differences were observed in the PFC, $t(14)=$ $1.966, p=.069$, or DS, $t(14)=.089, p=.932$ (Figure 2C). No correlation was observed between endocannabinoid levels and total cocaine intake (Supplemental Figure 3). 


\subsection{Alteration of CB1 receptor expression following cocaine self-administration}

Western blot analysis was performed to examine whether $C n r l$ expression changes observed at the RNA level could be attributed to modulation of the receptor protein expression. This analysis revealed a significant increase in CB1R expression in both the PFC, $t(7)=2.787, p=.027$ and DS, $t(7)=2.380, p=.048$ following cocaine-SA, and a trend to an increase in the HPC, $t(8)=2.316, p=.054($ See Figure 3A, B).

\subsection{Modulation of CB1R functional activity following cocaine self-administration}

To evaluate whether molecular changes observed for Cnrl expression are accompanied by adaptations at the functional level of the receptor, we assessed agoniststimulated $\left[{ }^{35} \mathrm{~S}\right]-\mathrm{GTP} \gamma \mathrm{S}$ binding. This assay revealed significantly increased efficacy (Emax) in cocaine-SA rats, compared to saline controls, in the HPC (Emax: Saline-Control $=153.4 \pm$ 14.81; Cocaine-SA = $218 \pm 15.95 ; H P C: p=0.011)$ (Figure 3C, D, E). The potency (EC50) was not altered in this region $\left(E C 50\right.$ : $\mathrm{Control}=15.310^{-8} \mathrm{M} \pm 7.1$; Cocaine-SA $=4.210^{-8} \mathrm{M} \pm$ 0.9 ) and there were no significant changes of either Emax or EC50 in the PFC or DS (data not shown). No correlation was observed between Emax and total cocaine intake (Supplemental Figure 3).

\subsection{Enrichment of histone modification changes following cocaine self-administration}

Chromatin immunoprecipitation (ChIP) experiments were conducted to examine whether transcriptional regulation observed for some endocannabinoid system genes in the HPC could be attributed to epigenetic regulations. We chose to focus on $\mathrm{H} 3 \mathrm{~K} 4 \mathrm{Me} 3$ and H3K27ac, since they represent two major modifications enriched at active promoters [18, 67]. Enrichment at Cnrl remained unchanged for both markers [H3K4Me3: Cnrl-prom, $p=$ 0.638; H3K27Ac Cnr1-prom: $p=0.229$; Cnrl-exon1: $\mathrm{p}=0.176$ ] (Figure 4A). These results indicate no significant change in histone modification in the HPC following cocaine-SA for Cnrl. In contrast, increased H3K4Me3 in Faah and Dagla promoter genes in response to cocaine was observed (Faah: $p=0.011$; Dagla: $p=0.039$ ) as well as increased H3K27Ac for Faah (Faah-prom: $p=0.038$; Faah-exonl: $\mathrm{p}=0.007)$ (Figure 4A).

\subsection{Chromosome conformation capture at Cnrl promoter locus}

Neuronal activation, including stimulation by drugs of abuse, leads to major remodeling of three-dimensional chromatin architecture supporting transcriptional reprogramming [68-70]. To investigate whether transcriptional induction of $C n r l$ in response to cocaine might result from spatial chromatin organization, we performed $4 \mathrm{C}$-seq analysis, targeting Cnrl. 4C-seq analysis targeting Cnrl promoter indicated that 3D chromatin architecture at $\mathrm{Cnrl}$ locus was substantially changed following cocaine-SA. Moreover, our 
data suggest that spatial organization of the chromatin at $C n r l$ locus is partially conserved between the HPC and NAc (Figure 4B, 4C and Supplemental Figure 5).

\section{Discussion}

Our work confirms that the endocannabinoid system is modulated by cocaine intake in rats. More precisely, self-administered cocaine modified cannabinoid signaling in brain reward regions, most notably, CB1Rs in the HPC. Epigenetic processes, including histone marks regulation and spatial chromatin re-organization at specific endocannabinoid genes, accompanied transcriptional changes. These modifications, therefore, may contribute to longlasting effects of chronic cocaine, including behavioral consequences.

\section{Endocannabinoid regulation in the HPC following cocaine-SA}

The HPC plays a critical role in learning and memory; in the context of substance use disorder, the region is implicated in the formation of drug-context and drug-cue associations, as well as reconsolidation of drug-associated memories. This brain structure is also linked to reinstatement of drug-taking, a behavior linked to relapse in humans (for a recent review, see [71]). As such, the HPC is an important component of the addiction circuit [72]. Indeed, our results point to significant molecular changes in this brain structure following cocaine-SA, with increased gene expression of the four main metabolizing enzymes, suggesting a remodeling of endocannabinoid tonus. Also, $\mathrm{Cnrl}$ expression was markedly increased in the cocaine-SA group, suggesting voluntary cocaine intake was associated with increased functionality of the receptor. CriplA expression in the HPC was also increased in this condition. As Crip1A enhances CB1R signaling in the HPC [73], this protein could participate in the regulation of CB1R signaling. Few studies have examined CB1R changes in the HPC following cocaine-SA and no changes could be detected at the protein level, using immunohistochemistry [74]. On the contrary, CB1R were increased in a cocaine sensitization paradigm in mice [43], possibly reflecting a compensatory mechanism as this modification was coupled with decreased gene/protein expression of the endocannabinoid-synthesis enzymes NAPE-PLD and DAGL $\alpha$ [43].

Endocannabinoid levels in the limbic forebrain are regulated following cocaine-SA with 2-AG unchanged [49], or decreased [48], the latter specifically in the NAc of short access rats [75]. Interestingly, both 2-AG and AEA were increased in the HPC only in cocaine-SA rats, matching previous results using a reinstatement paradigm [74]. Similar 
increases in 2-AG were observed in rats receiving passive cocaine injections (yoked), whereas both AEA and 2-AG were reduced following extinction of cocaine-SA. This supports the idea that molecular adaptations to cocaine are not ubiquitous, but depend on the conditions of administration [50]. Importantly, we evaluated endocannabinoid levels $24 \mathrm{~h}$ after the last cocaine session in order to avoid changes due to acute drug effects, which may explain discrepancies with previous findings. Species and/or strain differences may also explain these differences given reports of varying levels of endocannabinoids in Lewis or Fisher rats under saline or cocaine-SA [47]. Specific regulations of endocannabinoids in the HPC point to a role of these lipid ligands in cocaine responses that may be involved in neuronal activity or memory processes. Previous studies have revealed a differential role for AEA and 2-AG in memory responses [76], with AEA being a central component in the modulation of memory consolidation, highlighting the complexity of the endocannabinoid system in such processes.

CB1Rs are mainly expressed on GABAergic neurons of the HPC [77] where they modulate synaptic plasticity and play a role in cognition [78]. Recent research using conditional knockout animals and chemogenetic approaches have dissociated discrete circuits and specific cell types expressing CB1Rs to explore underlying mechanisms involved in drugassociated memory [79-81]. In particular, depending on their cell-type localization, CB1Rs appear to differentially control cellular and molecular effects of cocaine, with CB1R expression in forebrain GABAergic neurons and cortical glutamatergic neurons controlling sensitivity to cocaine and associative learning, respectively [35]. These results highlight a role of the hippocampal endocannabinoid system in cocaine responses, which may reflect the region's involvement in learning and memory processes [82, 83]. Other brain circuits, including distinct striatal neuronal subtypes [84] or discrete brain structures like the basolateral amygdala [85], may contribute to the formation of cocaine-environment associations. These results highlight the role of the endocannabinoid system in memory associated with cocaine intake and provide support for potential therapeutic strategies for relapse prevention. Altogether, such approaches will refine our continuously evolving knowledge of endocannabinoid signaling and further the understanding of the involvement of adaptations in specific brain structures following cocaine abuse.

\section{Opposite role of CB1Rs and CB2Rs in cocaine adaptations}

Interestingly, some studies have revealed similar roles for CB1Rs and CB2Rs in responses to cocaine. Pharmacological blockade of either CB1Rs or CB2Rs prevented both cocaine-induced conditioned locomotion and cocaine-induced reduction of cell proliferation 
in the HPC of adult male rats [86]. Common regulation of both receptors in the PFC was described with a decreased expression in a cocaine-SA paradigm [46], and an increased expression in a cocaine-SA reinstatement paradigm [74]. Nevertheless, as in our study, some findings support opposite regulations and opposing roles for the two receptors. We observed increased transcript levels of CB1Rs in the NAc, DS, and HPC whereas CB2R expression decreased significantly in the PFC and DS following cocaine self-administration. In a mouse model of spontaneous cocaine withdrawal, a decrease and increase were reported in the NAc for $\mathrm{CB} 1 \mathrm{R}$ and $\mathrm{CB} 2 \mathrm{R}$ transcripts, respectively [87]. Opposite patterns of protein expression were reported for CBRs in basal conditions in adolescent, compared to adult, rats (CB1R higher and CB2R lower) in both the PFC and HPC. When cocaine was administered during early adolescence, CB1R levels were increased while CB2R were decreased, only in the PFC [88]. Another study revealed opposite effects for CB1R and CB2R using cocainesensitization and CPP tests in mice. Specifically, a CB1R antagonist (AM251) inhibited the acquisition and expression of sensitization and the acquisition of a CPP, whereas a CB2R agonist (JWH133) inhibited acquisition and expression of both sensitization and CPP. These interventions also blocked neuronal activation in the HPC of CPP-exposed animals, suggesting an opposite role for the two receptors, specifically through HPC activation [89]. In another study, a CB1R antagonist (Rimonabant) or CB2R agonist (JWH133) attenuated cocaine-induced hyperlocomotion, and the effect of Rimonabant was reversed by blocking CB2Rs [42]. Interestingly, this reciprocal interaction between CB1R blockade and CB2R activation on cocaine responses was correlated with neuronal activation in the NAc [42]. Similarly, a CB2R antagonist reversed the inhibitory effect of Rimonabant on a cocaineinduced CPP [42]. Such reciprocal interactions were also observed on acquisition and expression of a CPP to cocaine, which were reduced by either a CB2R agonist (JWH133) or a CB1R antagonist (Rimonabant) [90]. The locomotor activity effects of cocaine were modulated in the same way [90]. Altogether, findings suggest a reciprocal interaction within the endocannabinoid system for modulating the reinforcing and psychomotor effects of cocaine. As discussed previously, this may occur through specificity of neurons expressing CB1Rs and CB2Rs, as recently described in the VTA [28, 91, 92]. Also, both CBRs are expressed on microglia and modulate neuroinflammatory processes, which may contribute to the pathophysiology of cocaine addiction (reviewed in [93]). It is therefore reasonable to propose that modification of endocannabinoid signaling and the reciprocal functioning of CBRs may alter production of inflammatory mediators, consequently altering cocaine-evoked behaviors $[93,94]$. 


\section{Epigenetic mechanisms involved in cocaine induced regulation of endocannabinoid genes}

To investigate epigenetic changes induced by cocaine-SA in the HPC, we first performed ChIP experiments targeting genes controlling endocannabinoid signaling, using H3K4Me3 and H3K27Ac marks, enriched at promoters and/or enhancers of active genes [95, 96]. Previous studies examining histone modifications following cocaine intake focused on the NAc [18], but few investigated such epigenetic changes in the HPC. H3K4me3 and H3K27ac levels were increased at regulatory regions of Faah following cocaine-SA, suggesting epigenetic mechanisms may drive transcriptional changes. Additional epigenetic mechanisms might contribute to transcriptional regulations induced by cocaine, including DNA methylation, as already proposed by previous studies in models of eating disorders [97100], and other psychiatric conditions [101]. Interestingly, two human studies surveying genome-wide changes reported gene expression and dynamic histone methylation modifications (including $\mathrm{H} 3 \mathrm{~K} 4 \mathrm{Me} 3$ ) in postmortem hippocampal tissue from individuals chronically exposed to cocaine, highlighting complex gene-regulatory process that may include multifaceted histone modifications [102, 103]. Second, we investigated 3D chromatin architecture using 4C-seq following cocaine-SA, as previous work demonstrated threedimensional chromatin remodeling supporting transcriptional reprogramming in the NAc following cocaine intake [70]. Our results on $\mathrm{Cnrl}$ locus indicate that cocaine induces remodeling of chromatin loops in the HPC, as well as in the NAc, supporting the idea that epigenetic mechanisms contribute to altered regulation of hippocampal endocannabinoid systems in response to cocaine.

\section{Sex differences in cocaine modulation of endocannabinoid signaling}

Epigenetic changes in response to cocaine exposure appear likely to be sex-specific [97]. Even though more men use or abuse cocaine, women may be more prone to become addicted following recreational use as they experience enhanced positive subjective effects of the drug (for a review see [104]). Once addicted to cocaine, women have more difficulty quitting and report higher levels of craving. Both sociocultural and biological factors may contribute to these sex differences, and recent studies highlight the role of sex hormones in reward processing [105]. For example, female rodents are more motivated to self-administer cocaine under a PR schedule, and estradiol enhances this effect [104, 106]. In addition, signaling of this hormone increases rewarding effects of cocaine in male, but not female, rats [107]. Together, these changes point to differential adaptions of the endocannabinoid system 
following drug exposure in males and females, that could be further studied to characterize underlying mechanism linking sex and endocannabinoid interactions in cocaine-induced effects.

\section{Future studies}

The current results represent the foundation for future work, examining which cocaine-induced epigenetic changes causally contribute to drug addiction mechanisms. Such functional validation experiments could focus on modifying specific epigenetic changes during cocaine self-administration and would involve a comprehensive and thorough analysis of molecular changes linked to specific behavioral measures. Based on current evidence, it is difficult to untangle whether manipulations of chromatin remodeling proteins cause, or simply correlate with, epigenetic regulations in rodent models of addiction [108]. Our previous work examining cocaine-induced alterations of DNA methylation in the PFC demonstrated that DNA methyltransferase (DNMT) inhibitors enhanced the reinforcing properties of cocaine, highlighting specific networks involved in underlying plasticity mechanisms [109]. Nevertheless, unanticipated findings including no major global methylation reaction, more hyper than hypomethylated DMRs following treatment with the DNMT inhibitor, and common differentially methylated genes in both untreated and treated groups highlighted the complexity of cocaine-induced epigenetic regulations. In addition, it is important to emphasize that gene-regulatory processes may include multifaceted epigenetic regulations such as histone modifications associated with DNA methylation. Interestingly, a recent study demonstrated that disrupting HDAC3 histone deacetylase activity altered target-specific changes in gene expression and synaptic plasticity in the NAc following cocaine exposure, but had no effect on behavioral responses to cocaine [110]. This provides further evidence for the complexity of epigenetic mechanisms driving cocaine-related behaviors, and emphasize the difficulty of establishing causal relationships with a single set of experiments. Cell-typespecific analyses and epigenome-editing tools may represent a crucial advance in the study of causal epigenetic mechanisms underlying cocaine addiction, ultimately, these may be used to design novel and more effective therapies for addiction [108]. 


\section{Declarations}

\section{Funding}

This project was supported by the Université de Strasbourg, Centre National de la Recherche Scientifique (CNRS), Programme International de Cooperation Scientifique (PICS CNRS), the Natural Sciences and Engineering Research Council of Canada (NSERC), and the Agence Nationale de la Recherche (ANR-2017-CE12-0027). DN received a PhD fellowship from the French Ministère de l'Enseignement Supérieur et de la Recherche and a fourth year $\mathrm{PhD}$ fellowship from the Fonds Paul Mandel. RAV was supported by post-doctoral fellowship from IdEx fellowship program (Université de Strasbourg).

Conflict of interest. The authors declare no conflict of interest.

\section{Data availability statement}

All the data supporting the findings of this study can be provided upon request from the corresponding author.

\section{Code availability N/A}

\section{Author's contribution}

Conceptualization: DN, JZ, and KB designed the experiments. Investigation: DN, PR, VA, DF, RAV, KB performed the experiments; DN, RB, JZ, RAV, MCO and KB analyzed the data and designed the figures; RAV and KM designed and analyzed epigenetic experiments; YG, VA contributed to the design and analysis of the mass spectrometry experiment. Supervision: KB supervised the study and wrote the paper with DN and MCO. All authors approved the final version of the manuscript.

\section{Acknowledgments}

We thank E Rizkallah for help with biochemical analysis and O. Bildstein, D. Egesi, and G. Edomwonyi for assistance with animal care.

Ethics approval Procedures and animal care were performed according to the European Union laws for animal studies and approved by the local ethics committee (CREMEAS) and the French Research Ministry (APAFIS\#2015012716049550).

\section{Consent to participate N/A}

\section{Consent for publication N/A}




\section{Figure Captions}

Figure 1. Cocaine-SA alters endocannabinoid system gene expression in brain reward areas. Rats responded for intravenous cocaine $(0.33 \mathrm{mg} / \mathrm{kg} / \mathrm{infusion})$ or the same volume of saline under a fixed ratio (FR1) schedule of reinforcement over 10 days ( $2 \mathrm{~h} /$ day). Behavioral data are shown as mean $( \pm$ SEM) number of injections $(A)$ and nose-pokes in active and inactive holes (B) per day over 10 sessions. A. Cocaine, but not saline, sustained responding under an FR1 schedule, with the cocaine-SA group discriminating between active and inactive nose-pokes by session 5 (B). Endocannabinoid system gene expression for cocaine-SA and saline-SA groups is shown as mean $( \pm$ SEM) mRNA levels of endocannabinoid system transcripts (C) or enzymes (D) in the PFC (n=6-9/group), NAc ( $n=4-10 /$ group), DS ( $n=4-$ 11/group) and HPC ( $n=5-9 /$ group). C. Cocaine-SA increased Cnrl gene expression in the NAc, DS and HPC, but decreased Cnr2 gene expression in the PFC and DS. D. Cocaine-SA increased gene expression of all endocannabinoid enzymes in the HPC. Cnr1/2: cannabinoid receptor 1/2; Cnrip1: cannabinoid receptor interacting protein 1A; Dagla: diacylglycerol lipase alpha; DS: dorsal striatum; Faah: fatty acide amine hydrolase; HPC: hippocampus; IP: intraperitoneal, NAc: nucleus accumbens; Napepld: $\mathrm{N}$-acyl phosphatidylethanolamine phospholipase D; $M g l l$ : monoacylglycerol lipase, PFC: prefrontal cortex; SA: selfadministration. $*=$ different from Saline-SA: * $p<.05, * *: p<.01$ and ${ }^{* *}: p<.001$.

Figure 2. Cocaine self-administration modulates endocannabinoid levels in brain reward areas. Individual expression levels of AEA and 2-AG in all samples illustrating brain structure distribution (A). Data are presented as group means $( \pm$ SEM) of endocannabinoid levels (B, C, n=7-8/group) in the PFC, NAc, DS, and HPC. Cocaine-SA decreased AEA levels in the NAc and DS (B). AEA levels in the HPC (B) and 2-AG levels in the NAc and HPC (C) were increased following cocaine-SA. Cocaine-SA increased CB1R expression in the PFC and DS. 2-AG: 2-arachidonoylglycerol; AEA: anandamide; CB1: cannabinoid receptor 1; DS: dorsal striatum; HPC: hippocampus, NAc: nucleus accumbens; PFC: prefrontal cortex; SA: self-administration. ${ }^{*}=$ different from Saline-SA: $*: p<.05$, and ${ }^{* *}: p<$ .01 .

Figure 3. Cocaine self-administration modulates CB1R expression and functionality in the prefrontal cortex, dorsal striatum and hippocampus. Data are presented as mean $( \pm$ SEM) relative $\mathrm{CB} 1 \mathrm{R}$ expression $(\mathbf{A}, \mathbf{B})$, and protein activation levels in the PFC $(\mathbf{C}), \mathrm{DS}$ 
(D) and HPC (E), as a percentage stimulation of CB1R per molar concentration of ACEA. Representative Western blots (A) and quantification (B) are represented ( $\mathrm{n}=4-5 /$ group). Cocaine-SA elevated CB1R maximal activation in the HPC but had no effect on CB1R activation in the PFC or DS (B, C, D) (Saline-SA, n=6-7; Cocaine-SA, n=7-9). ACEA: Arachidonyl-2'-chloroethylamide; DS: dorsal striatum; GTP $\gamma \mathrm{S}$ : guanosine 5'-[ $\gamma$ thio]triphosphate; DS: dorsal striatum; HPC: hippocampus; PFC: prefrontal cortex; SA: selfadministration. ${ }^{*}=$ different from Saline-SA, $p<.05$.

Figure 4. Cocaine self-administration alters histone modifications and chromatin looping on endocannabinoid system-associated genes in the hippocampus. (A) Data are presented as mean $( \pm \mathrm{SEM})$ percentage of histone modification enrichment compared to Saline-SA for each region of interest. Cocaine-SA increased H3K4Me3 enrichment on promotor regions of Faah and Dagla coding-genes. Cocaine-SA also increased H3K27Ac enrichment in the HPC on promotor and exon 1 regions of the Faah gene (n=5-7/group). * = different from Saline-SA: *: $p<.05, * *: p<.01$ and ***: $p<.001$. (B) Cnrl promoter chromatin interactions are modulated by cocaine-SA in a tissue-dependent manner. 4C-seq area-proportional Chow-Ruskey plots show the overlap between significant promoter interacting regions detected in $4 \mathrm{C}$-seq data across the different experimental conditions (HPC Sal-SA, HPC Cocaine-SA, NAc Saline-SA, Nac Cocaine-SA). For each dataset, a delimited area proportional to the coverage of detected promoter interaction in nucleotides is delineated by a different border line pattern. Common interacting regions between different datasets are shown by increasingly darker grey tonalities according to the number of datasets intersecting together, with the central circle representing the overlap of all datasets (dark grey) and the more external areas representing non-overlapping regions (white). Numbers account for the nucleotides present in the comprising area. (C) 3D chromatin remodeling index showing cocaine-SA induced changes at Cnrl locus for hippocampus (HPC) and nucleus accumbens (NAc), calculated as: (number of nucleotides specific to Cocaine-SA) / (total number of nucleotides obtained for Saline-SA). Dagla: diacylglycerol lipase alpha; Faah: fatty acid amine hydrolase; SA: self-administration.

Supplemental Table 1. Microdissected areas.

Supplemental Table 2. Primer sequences for reference (Rplp0) and endocannabinoid system genes for qPCR, ChIP-PCR and 4C analysis.

Supplemental Table 3. Mass spectrometry analysis were performed on a Dionex Ultimate 3000 HPLC system coupled with a triple quadrupole Endura mass spectrometer (Thermo 
Scientific, San Jose, USA) and controlled by Xcalibur v. 2.0 software. The presence of 2-AG, AEA, D8-2-AG and D5-AEA was examined using the multiple reaction monitoring mode (MRM). For the elution, mobile phase A corresponded to ACN 1\% / $\mathrm{H}_{2} \mathrm{O} 98.9 \%$ / formic acid $0.1 \%(\mathrm{v} / \mathrm{v} / \mathrm{v})$, whereas mobile phase B was ACN $99.9 \%$ / formic acid $0.1 \%$ (v/v). For electrospray ionisation, desolvation (nitrogen) sheath gas was set to 10 Arb and Aux gas was set to $5 \mathrm{Arb}$. The Ion transfer tube was heated at $287^{\circ} \mathrm{C}$. Q1 and Q2 resolutions were set at 0.7 FWHM, whereas collision gas (CID, argon) was set to 2 mTorr. Selection of the monitored transitions and optimization of collision energy and RF Lens parameters were manually determined. All amounts of endocannabinoids measured in samples fit within the standard curve limits, with typical analytical ranges from $1 \mathrm{fmol}-100 \mathrm{pmol}$ to $150 \mathrm{fmol}-100$ pmol. Precision (CV\% between repeated injections of the same sample) values were $<1 \%$ for sameday measurements and $<5 \%$ for inter-day measurements.

Supplemental Figure 1. Timeline of experimental procedures. Cocaine self-administration (SA) effects were examined on endocannabinoid system processes. Rats responded for intravenous cocaine $(0.33 \mathrm{mg} / \mathrm{kg} /$ infusion $)$ or the same volume of saline under a fixed ratio (FR1) schedule of reinforcement over 10 days (2 h/day). Independent cohorts were processed and samples were used for molecular investigation. GTP $\gamma \mathrm{S}$ binding and gene expression (cohort 1) and Western blot analysis and gene expression (cohort 2) were from same rat samples; in cohort 4, Mass Spectrometry and 4C analysis were performed from distinct animals.

\section{Supplemental Figure 2: Cocaine-SA alters endocannabinoid system gene expression in} brain reward areas. Endocannabinoid system gene expression for cocaine-SA and saline-SA groups is shown as mean $( \pm \mathrm{SEM})$ in the habenula (Hab, $n=4-11$ /group), Amygdala (Amy, $n=$ 6-10/group), lateral hypothalamus ( $\mathrm{LH}, \mathrm{n}=4-7 /$ group), ventral tegmental area (VTA, n=58/group) and tail of the ventral tegmental area (RMTg, $n=4-7 /$ group).

Supplemental Figure 3: Correlation analysis. Correlation plots between cocaine total intake and endocannabinoid levels (AEA and 2-AG), Cnrl expression, or Emax values, in brain reward areas. DS: dorsal striatum; HPC: hippocampus, NAc: nucleus accumbens; PFC: prefrontal cortex.

Supplemental Figure 4: Cocaine-SA modulates CB1R expression in brain reward areas. Representative Western blots for Figure 4D in PFC, DS and HPC samples following cocaineSA experiments (A). Representative Western blots in mouse brain samples for CB1R, in wildtype (WT), knockout mouse for CB1R (Cnr1 ko) and knockout mouse for CB2R (Cnr2 ko) 
for antibody validation (B). DS: dorsal striatum; HPC: hippocampus; PFC: prefrontal cortex; SA: self-administration.

\section{Supplemental Figure 5: Circular chromatin conformation capture (4C-seq) at Cnr1}

promoter. 4C-seq profiles at $\mathrm{Cnrl}$ locus generated using saline self-administrated (SalineSA, light grey) and cocaine self-administrated (Cocaine-SA, black) rat hippocampus (HPC) and nucleus accumbens (NAc). On the y axis, quantile normalized reads for each 4C-seq dataset show the signal coverage of $\mathrm{Cnrl}$ interacting regions. Boxes below each data track illustrate the significant interactions detected for each bait and condition. H3K27ac ChIPseq coverage (black) from rat hypothalamus (GSM2520838), shows how some Cnrl distal regulatory regions are enriched at active promoter and enhancer regions. Gene annotations are included in the bottom track [111]. 


\section{References}

1. Volkow ND, Koob GF, McLellan AT. (2016). Neurobiologic Advances from the Brain Disease Model of Addiction. N Engl J Med, 374, 363-71. doi:10.1056/NEJMra1511480

2. Justice CfS. (2013). No quick fix: Exposing the depth of Britain's drug and alcohol problem. London, UK.

3. Olesen J, Gustavsson A, Svensson M, Wittchen HU, Jonsson B, group Cs et al. (2012). The economic cost of brain disorders in Europe. Eur J Neurol, 19, 155-62. doi:10.1111/j.14681331.2011.03590.x

4. EMCDDA. European Drug Report 2021: Trends and Developments: Lisbon, 2021.

5. Kim ST, Park T. (2019). Acute and Chronic Effects of Cocaine on Cardiovascular Health. Int J Mol Sci, 20. doi:10.3390/ijms20030584

6. D'Souza MS. (2019). Brain and Cognition for Addiction Medicine: From Prevention to Recovery Neural Substrates for Treatment of Psychostimulant-Induced Cognitive Deficits. Front Psychiatry, 10, 509. doi:10.3389/fpsyt.2019.00509

7. Koob GF, Volkow ND. (2016). Neurobiology of addiction: a neurocircuitry analysis. Lancet Psychiatry, 3, 760-773. doi:10.1016/S2215-0366(16)00104-8

8. Robinson TE, Kolb B. (1999). Alterations in the morphology of dendrites and dendritic spines in the nucleus accumbens and prefrontal cortex following repeated treatment with amphetamine or cocaine. European Journal of Neuroscience, 11, 1598-1604. doi:10.1046/j.1460-9568.1999.00576.x

9. Ron D, Jurd R. (2005). The "ups and downs" of signaling cascades in addiction. Sci STKE, 2005, re14

10. Bonci A, Williams JT. (1996). A common mechanism mediates long-term changes in synaptic transmission after chronic cocaine and morphine. Neuron, 16, 631-9. doi:10.1016/s08966273(00)80082-3

11. Buck SA, Torregrossa MM, Logan RW, Freyberg Z. (2021). Roles of dopamine and glutamate co-release in the nucleus accumbens in mediating the actions of drugs of abuse. FEBS J, 288, 1462-1474. doi:10.1111/febs.15496

12. De Deurwaerdere P, Di Giovanni G. (2017). Serotonergic modulation of the activity of mesencephalic dopaminergic systems: Therapeutic implications. Prog Neurobiol, 151, 175236. doi:10.1016/j.pneurobio.2016.03.004

13. Lappin JM, Sara GE. (2019). Psychostimulant use and the brain. Addiction, 114, 2065-2077. doi:10.1111/add.14708

14. McClung CA, Nestler EJ, Zachariou V. (2005). Regulation of gene expression by chronic morphine and morphine withdrawal in the locus ceruleus and ventral tegmental area. $J$ Neurosci, 25, 6005-15 
15. Russo SJ, Dietz DM, Dumitriu D, Morrison JH, Malenka RC, Nestler EJ. (2010). The addicted synapse: mechanisms of synaptic and structural plasticity in nucleus accumbens. Trends Neurosci, 33, 267-76

16. Bali P, Kenny PJ. (2013). MicroRNAs and Drug Addiction. Front Genet, 4, 43. doi:10.3389/fgene.2013.00043

17. Baratta AM, Rathod RS, Plasil SL, Seth A, Homanics GE. (2021). Exposure to drugs of abuse induce effects that persist across generations. Int Rev Neurobiol, 156, 217-277. doi:10.1016/bs.irn.2020.08.003

18. De Sa Nogueira D, Merienne K, Befort K. (2019). Neuroepigenetics and addictive behaviors: Where do we stand? Neurosci Biobehav Rev, 106, 58-72. doi:10.1016/j.neubiorev.2018.08.018

19. Mews P, Calipari ES, Day J, Lobo MK, Bredy T, Abel T. (2021). From Circuits to Chromatin: The Emerging Role of Epigenetics in Mental Health. J Neurosci, 41, 873-882. doi:10.1523/JNEUROSCI.1649-20.2020

20. Befort K. (2015). Interactions of the opioid and cannabinoid systems in reward: Insights from knockout studies. Frontiers in pharmacology, 6, 6. doi:10.3389/fphar.2015.00006

21. Panagis G, Mackey B, Vlachou S. (2014). Cannabinoid Regulation of Brain Reward Processing with an Emphasis on the Role of CB1 Receptors: A Step Back into the Future. Front Psychiatry, 5, 92. doi:10.3389/fpsyt.2014.00092

22. Zimmer A. (2015). Genetic Manipulation of the Endocannabinoid System. Handb Exp Pharmacol, 231, 129-83. doi:10.1007/978-3-319-20825-1_5

23. Freund TF, Katona I, Piomelli D. (2003). Role of endogenous cannabinoids in synaptic signaling. Physiol Rev, 83, 1017-66. doi:10.1152/physrev.00004.2003

24. Navarrete M, Diez A, Araque A. (2014). Astrocytes in endocannabinoid signalling. Philos Trans $R$ Soc Lond B Biol Sci, 369, 20130599. doi:10.1098/rstb.2013.0599

25. Li Y, Kim J. (2015). Neuronal expression of CB2 cannabinoid receptor mRNAs in the mouse hippocampus. Neuroscience, 311, 253-67. doi:10.1016/j.neuroscience.2015.10.041

26. Onaivi ES, Ishiguro H, Gong JP, Patel S, Perchuk A, Meozzi PA et al. (2006). Discovery of the presence and functional expression of cannabinoid CB2 receptors in brain. Ann N Y Acad Sci, 1074, 514-36. doi:10.1196/annals.1369.052

27. Stempel AV, Stumpf A, Zhang HY, Ozdogan T, Pannasch U, Theis AK et al. (2016). Cannabinoid Type 2 Receptors Mediate a Cell Type-Specific Plasticity in the Hippocampus. Neuron, 90, 795-809. doi:10.1016/j.neuron.2016.03.034

28. Zhang HY, Gao M, Shen H, Bi GH, Yang HJ, Liu QR et al. (2017). Expression of functional cannabinoid CB2 receptor in VTA dopamine neurons in rats. Addict Biol, 22, 752-765. doi:10.1111/adb.12367

29. Booth WT, Walker NB, Lowther WT, Howlett AC. (2019). Cannabinoid Receptor Interacting Protein 1a (CRIP1a): Function and Structure. Molecules, 24. doi:10.3390/molecules24203672

30. Oliver EE, Hughes EK, Puckett MK, Chen R, Lowther WT, Howlett AC. (2020). Cannabinoid Receptor Interacting Protein 1a (CRIP1a) in Health and Disease. Biomolecules, 10. doi:10.3390/biom10121609 
31. Pertwee RG. (2015). Endocannabinoids and Their Pharmacological Actions. Handb Exp Pharmacol, 231, 1-37. doi:10.1007/978-3-319-20825-1_1

32. De Vries TJ, Shaham Y, Homberg JR, Crombag H, Schuurman K, Dieben J et al. (2001). A cannabinoid mechanism in relapse to cocaine seeking. Nat Med, 7, 1151-4. doi:10.1038/nm1001-1151

33. Soria G, Mendizabal V, Tourino C, Robledo P, Ledent C, Parmentier M et al. (2005). Lack of CB1 cannabinoid receptor impairs cocaine self-administration. Neuropsychopharmacology, 30, 1670-80. doi:10.1038/sj.npp.1300707

34. Maldonado R, Valverde O, Berrendero F. (2006). Involvement of the endocannabinoid system in drug addiction. Trends Neurosci, 29, 225-32. doi:10.1016/j.tins.2006.01.008

35. Martin-Garcia E, Bourgoin L, Cathala A, Kasanetz F, Mondesir M, Gutierrez-Rodriguez A et al. (2016). Differential Control of Cocaine Self-Administration by GABAergic and Glutamatergic CB1 Cannabinoid Receptors. Neuropsychopharmacology, 41, 2192-205. doi:10.1038/npp.2015.351

36. Xi ZX, Peng XQ, Li X, Song R, Zhang HY, Liu QR et al. (2011). Brain cannabinoid $C B(2)$ receptors modulate cocaine's actions in mice. Nat Neurosci, 14, 1160-6. doi:10.1038/nn.2874

37. Zhang HY, Gao M, Liu QR, Bi GH, Li X, Yang HJ et al. (2014). Cannabinoid CB2 receptors modulate midbrain dopamine neuronal activity and dopamine-related behavior in mice. Proc Natl Acad Sci U S A, 111, E5007-15. doi:10.1073/pnas.1413210111

38. Scherma M, Qvist JS, Asok A, Huang SC, Masia P, Deidda M et al. (2020). Cannabinoid exposure in rat adolescence reprograms the initial behavioral, molecular, and epigenetic response to cocaine. Proc Natl Acad Sci U S A, 117, 9991-10002. doi:10.1073/pnas.1920866117

39. Mereu M, Tronci V, Chun LE, Thomas AM, Green JL, Katz JL et al. (2015). Cocaine-induced endocannabinoid release modulates behavioral and neurochemical sensitization in mice. Addict Biol, 20, 91-103. doi:10.1111/adb.12080

40. Justinova Z, Mangieri RA, Bortolato M, Chefer SI, Mukhin AG, Clapper JR et al. (2008). Fatty acid amide hydrolase inhibition heightens anandamide signaling without producing reinforcing effects in primates. Biol Psychiatry, 64, 930-7.

doi:10.1016/j.biopsych.2008.08.008

41. Adamczyk P, McCreary AC, Przegalinski E, Mierzejewski P, Bienkowski P, Filip M. (2009). The effects of fatty acid amide hydrolase inhibitors on maintenance of cocaine and food selfadministration and on reinstatement of cocaine-seeking and food-taking behavior in rats. J Physiol Pharmacol, 60, 119-25

42. Gobira PH, Oliveira AC, Gomes JS, da Silveira VT, Asth L, Bastos JR et al. (2019). Opposing roles of $\mathrm{CB} 1$ and $\mathrm{CB} 2$ cannabinoid receptors in the stimulant and rewarding effects of cocaine. Br J Pharmacol, 176, 1541-1551. doi:10.1111/bph.14473

43. Blanco E, Galeano P, Palomino A, Pavon FJ, Rivera P, Serrano A et al. (2016). Cocaine-induced behavioral sensitization decreases the expression of endocannabinoid signaling-related proteins in the mouse hippocampus. Eur Neuropsychopharmacol, 26, 477-92. doi:10.1016/j.euroneuro.2015.12.040

44. Blanco E, Pavon FJ, Palomino A, Luque-Rojas MJ, Serrano A, Rivera P et al. (2014). Cocaineinduced behavioral sensitization is associated with changes in the expression of 
endocannabinoid and glutamatergic signaling systems in the mouse prefrontal cortex. Int $J$ Neuropsychopharmacol, 18. doi:10.1093/ijnp/pyu024

45. Palomino A, Pavon FJ, Blanco-Calvo E, Serrano A, Arrabal S, Rivera P et al. (2014). Effects of acute versus repeated cocaine exposure on the expression of endocannabinoid signalingrelated proteins in the mouse cerebellum. Front Integr Neurosci, 8, 22. doi:10.3389/fnint.2014.00022

46. Bystrowska B, Frankowska M, Smaga I, Pomierny-Chamiolo L, Filip M. (2018). Effects of Cocaine Self-Administration and Its Extinction on the Rat Brain Cannabinoid CB1 and CB2 Receptors. Neurotox Res, 34, 547-558. doi:10.1007/s12640-018-9910-6

47. Rivera P, Miguens M, Coria SM, Rubio L, Higuera-Matas A, Bermudez-Silva FJ et al. (2013). Cocaine self-administration differentially modulates the expression of endogenous cannabinoid system-related proteins in the hippocampus of Lewis vs. Fischer 344 rats. Int J Neuropsychopharmacol, 16, 1277-93. doi:10.1017/S1461145712001186

48. Gonzalez S, Cascio MG, Fernandez-Ruiz J, Fezza F, Di Marzo V, Ramos JA. (2002). Changes in endocannabinoid contents in the brain of rats chronically exposed to nicotine, ethanol or cocaine. Brain Res, 954, 73-81. doi:10.1016/s0006-8993(02)03344-9

49. Caille S, Alvarez-Jaimes L, Polis I, Stouffer DG, Parsons LH. (2007). Specific alterations of extracellular endocannabinoid levels in the nucleus accumbens by ethanol, heroin, and cocaine self-administration. J Neurosci, 27, 3695-702. doi:10.1523/JNEUROSCI.4403-06.2007

50. Bystrowska B, Smaga I, Frankowska M, Filip M. (2014). Changes in endocannabinoid and Nacylethanolamine levels in rat brain structures following cocaine self-administration and extinction training. Prog Neuropsychopharmacol Biol Psychiatry, 50, 1-10. doi:10.1016/j.pnpbp.2013.12.002

51. De Sa Nogueira D, Bourdy R, Filliol D, Romieu P, Befort K. (2021). Hippocampal mu opioid receptors are modulated following cocaine self-administration in rat. Eur J Neurosci, 53, 3341-3349. doi:10.1111/ejn.15217

52. Paxinos G, Watson C. (2007). The rat brain in stereotaxic coordinates (6th edition ed.). Amsterdam/Boston: Elsevier/Academic press.

53. Schmid PC, Krebsbach RJ, Perry SR, Dettmer TM, Maasson JL, Schmid HH. (1995). Occurrence and postmortem generation of anandamide and other long-chain $\mathrm{N}$-acylethanolamines in mammalian brain. FEBS Lett, 375, 117-20. doi:10.1016/0014-5793(95)01194-j

54. Bourdy R, Hertz A, Filliol D, Andry V, Goumon Y, Mendoza J et al. (2021). The endocannabinoid system is modulated in reward and homeostatic brain regions following diet-induced obesity in rats: a cluster analysis approach. Eur J Nutr. doi:10.1007/s00394-02102613-0

55. de Sa Nogueira D, Bourdy R, Filliol D, Awad G, Andry V, Goumon Y et al. (2021). Binge sucrose-induced neuroadaptations: A focus on the endocannabinoid system. Appetite, 164, 105258. doi:10.1016/j.appet.2021.105258

56. Silberberg G, Baruch K, Navon R. (2009). Detection of stable reference genes for real-time PCR analysis in schizophrenia and bipolar disorder. Anal Biochem, 391, 91-7. doi:10.1016/j.ab.2009.05.026

57. Livak KJ, Schmittgen TD. (2001). Analysis of relative gene expression data using real-time quantitative PCR and the 2(-Delta Delta C(T)) Method. Methods, 25, 402-8.

doi:10.1006/meth.2001.1262 
58. Luszczki JJ, Czuczwar P, Cioczek-Czuczwar A, Czuczwar SJ. (2006). Arachidonyl-2'chloroethylamide, a highly selective cannabinoid CB1 receptor agonist, enhances the anticonvulsant action of valproate in the mouse maximal electroshock-induced seizure model. Eur J Pharmacol, 547, 65-74. doi:10.1016/j.ejphar.2006.07.037

59. Gurtler A, Kunz N, Gomolka M, Hornhardt S, Friedl AA, McDonald K et al. (2013). Stain-Free technology as a normalization tool in Western blot analysis. Anal Biochem, 433, 105-11. doi:10.1016/j.ab.2012.10.010

60. Alcala-Vida R, Seguin J, Lotz C, Molitor AM, Irastorza-Azcarate I, Awada A et al. (2021). Agerelated and disease locus-specific mechanisms contribute to early remodelling of chromatin structure in Huntington's disease mice. Nat Commun, 12, 364. doi:10.1038/s41467-02020605-2

61. Sexton T, Kurukuti S, Mitchell JA, Umlauf D, Nagano T, Fraser P. (2012). Sensitive detection of chromatin coassociations using enhanced chromosome conformation capture on chip. Nat Protoc, 7, 1335-50. doi:10.1038/nprot.2012.071

62. Langmead B, Trapnell C, Pop M, Salzberg SL. (2009). Ultrafast and memory-efficient alignment of short DNA sequences to the human genome. Genome Biol, 10, R25. doi:10.1186/gb-2009-10-3-r25

63. Ben Zouari Y, Platania A, Molitor AM, Sexton T. (2019). 4See: A Flexible Browser to Explore 4C Data. Front Genet, 10, 1372. doi:10.3389/fgene.2019.01372

64. Lopez-Delisle L, Rabbani L, Wolff J, Bhardwaj V, Backofen R, Gruning B et al. (2021). pyGenomeTracks: reproducible plots for multivariate genomic datasets. Bioinformatics, 37, 422-423. doi:10.1093/bioinformatics/btaa692

65. Khan A, Mathelier A. (2017). Intervene: a tool for intersection and visualization of multiple gene or genomic region sets. BMC Bioinformatics, 18, 287. doi:10.1186/s12859-017-1708-7

66. Buczynski MW, Parsons LH. (2010). Quantification of brain endocannabinoid levels: methods, interpretations and pitfalls. Br J Pharmacol, 160, 423-42. doi:10.1111/j.1476-

5381.2010.00787.x

67. Renthal W, Nestler EJ. (2008). Epigenetic mechanisms in drug addiction. Trends Mol Med, 14, 341-50. doi:10.1016/j.molmed.2008.06.004

68. Fernandez-Albert J, Lipinski M, Lopez-Cascales MT, Rowley MJ, Martin-Gonzalez AM, Del Blanco B et al. (2019). Immediate and deferred epigenomic signatures of in vivo neuronal activation in mouse hippocampus. Nat Neurosci, 22, 1718-1730. doi:10.1038/s41593-0190476-2

69. Marco A, Meharena HS, Dileep V, Raju RM, Davila-Velderrain J, Zhang AL et al. (2020). Mapping the epigenomic and transcriptomic interplay during memory formation and recall in the hippocampal engram ensemble. Nat Neurosci, 23, 1606-1617. doi:10.1038/s41593-02000717-0

70. Vaillancourt K, Yang J, Chen GG, Yerko V, Theroux JF, Aouabed Z et al. (2021). Cocaine-related DNA methylation in caudate neurons alters 3D chromatin structure of the IRXA gene cluster. Mol Psychiatry, 26, 3134-3151. doi:10.1038/s41380-020-00909-x

71. Kutlu MG, Gould TJ. (2016). Effects of drugs of abuse on hippocampal plasticity and hippocampus-dependent learning and memory: contributions to development and maintenance of addiction. Learn Mem, 23, 515-33. doi:10.1101/Im.042192.116 
72. Castilla-Ortega E, Serrano A, Blanco E, Araos P, Suarez J, Pavon FJ et al. (2016). A place for the hippocampus in the cocaine addiction circuit: Potential roles for adult hippocampal neurogenesis. Neurosci Biobehav Rev, 66, 15-32. doi:10.1016/j.neubiorev.2016.03.030

73. Guggenhuber S, Alpar A, Chen R, Schmitz N, Wickert M, Mattheus T et al. (2016). Cannabinoid receptor-interacting protein Crip1a modulates CB1 receptor signaling in mouse hippocampus. Brain Struct Funct, 221, 2061-74. doi:10.1007/s00429-015-1027-6

74. Bystrowska B, Frankowska M, Smaga I, Niedzielska-Andres E, Pomierny-Chamiolo L, Filip M. (2019). Cocaine-Induced Reinstatement of Cocaine Seeking Provokes Changes in the Endocannabinoid and N-Acylethanolamine Levels in Rat Brain Structures. Molecules, 24. doi:10.3390/molecules 24061125

75. Orio L, Edwards S, George O, Parsons LH, Koob GF. (2009). A role for the endocannabinoid system in the increased motivation for cocaine in extended-access conditions. J Neurosci, 29, 4846-57. doi:10.1523/JNEUROSCI.0563-09.2009

76. Busquets-Garcia A, Puighermanal E, Pastor A, de la Torre R, Maldonado R, Ozaita A. (2011). Differential role of anandamide and 2-arachidonoylglycerol in memory and anxiety-like responses. Biol Psychiatry, 70, 479-86. doi:10.1016/j.biopsych.2011.04.022

77. Marsicano G, Lutz B. (1999). Expression of the cannabinoid receptor CB1 in distinct neuronal subpopulations in the adult mouse forebrain. Eur J Neurosci, 11, 4213-25. doi:10.1046/j.1460-9568.1999.00847.x

78. Busquets-Garcia A, Bains J, Marsicano G. (2018). CB1 Receptor Signaling in the Brain: Extracting Specificity from Ubiquity. Neuropsychopharmacology, 43, 4-20. doi:10.1038/npp.2017.206

79. Busquets-Garcia A, Desprez T, Metna-Laurent M, Bellocchio L, Marsicano G, Soria-Gomez E. (2015). Dissecting the cannabinergic control of behavior: The where matters. Bioessays, 37, 1215-25. doi:10.1002/bies.201500046

80. Busquets-Garcia A, Oliveira da Cruz JF, Terral G, Pagano Zottola AC, Soria-Gomez E, Contini A et al. (2018). Hippocampal CB1 Receptors Control Incidental Associations. Neuron, 99, 12471259 e7. doi:10.1016/j.neuron.2018.08.014

81. Oliveira da Cruz JF, Busquets-Garcia A, Zhao Z, Varilh M, Lavanco G, Bellocchio L et al. (2020). Specific Hippocampal Interneurons Shape Consolidation of Recognition Memory. Cell Rep, 32, 108046. doi:10.1016/j.celrep.2020.108046

82. Davies SN, Pertwee RG, Riedel G. (2002). Functions of cannabinoid receptors in the hippocampus. Neuropharmacology, 42, 993-1007. doi:10.1016/s0028-3908(02)00060-6

83. Lupica CR, Hu Y, Devinsky O, Hoffman AF. (2017). Cannabinoids as hippocampal network administrators. Neuropharmacology, 124, 25-37. doi:10.1016/j.neuropharm.2017.04.003

84. Turner BD, Smith NK, Manz KM, Chang BT, Delpire E, Grueter CA et al. (2021). Cannabinoid type 1 receptors in $A 2 a$ neurons contribute to cocaine-environment association.

Psychopharmacology (Berl), 238, 1121-1131. doi:10.1007/s00213-021-05759-1

85. Higginbotham JA, Wang R, Richardson BD, Shiina H, Tan SM, Presker MA et al. (2021). CB1 Receptor Signaling Modulates Amygdalar Plasticity during Context-Cocaine Memory Reconsolidation to Promote Subsequent Cocaine Seeking. J Neurosci, 41, 613-629. doi:10.1523/JNEUROSCI.1390-20.2020 
86. Blanco-Calvo E, Rivera P, Arrabal S, Vargas A, Pavon FJ, Serrano A et al. (2014).

Pharmacological blockade of either cannabinoid CB1 or CB2 receptors prevents both cocaineinduced conditioned locomotion and cocaine-induced reduction of cell proliferation in the hippocampus of adult male rat. Front Integr Neurosci, 7, 106. doi:10.3389/fnint.2013.00106

87. Gasparyan A, Navarrete F, Rodriguez-Arias M, Minarro J, Manzanares J. (2021). Cannabidiol Modulates Behavioural and Gene Expression Alterations Induced by Spontaneous Cocaine Withdrawal. Neurotherapeutics, 18, 615-623. doi:10.1007/s13311-020-00976-6

88. Garcia-Cabrerizo R, Garcia-Fuster MJ. (2016). Opposite regulation of cannabinoid CB1 and $C B 2$ receptors in the prefrontal cortex of rats treated with cocaine during adolescence. Neurosci Lett, 615, 60-5. doi:10.1016/j.neulet.2016.01.018

89. Lopes JB, Bastos JR, Costa RB, Aguiar DC, Moreira FA. (2020). The roles of cannabinoid CB1 and $C B 2$ receptors in cocaine-induced behavioral sensitization and conditioned place preference in mice. Psychopharmacology (Berl), 237, 385-394. doi:10.1007/s00213-01905370-5

90. Delis F, Polissidis A, Poulia N, Justinova Z, Nomikos GG, Goldberg SR et al. (2017). Attenuation of Cocaine-Induced Conditioned Place Preference and Motor Activity via Cannabinoid CB2 Receptor Agonism and CB1 Receptor Antagonism in Rats. Int J Neuropsychopharmacol, 20, 269-278. doi:10.1093/ijnp/pyw102

91. Humburg BA, Jordan CJ, Zhang HY, Shen H, Han X, Bi GH et al. (2021). Optogenetic brainstimulation reward: $A$ new procedure to re-evaluate the rewarding versus aversive effects of cannabinoids in dopamine transporter-Cre mice. Addict Biol, 26, e13005. doi:10.1111/adb.13005

92. Zhang HY, Shen H, Gao M, Ma Z, Hempel BJ, Bi GH et al. (2021). Cannabinoid CB2 receptors are expressed in glutamate neurons in the red nucleus and functionally modulate motor behavior in mice. Neuropharmacology, 189, 108538. doi:10.1016/j.neuropharm.2021.108538

93. Rodrigues LC, Gobira PH, de Oliveira AC, Pelicao R, Teixeira AL, Moreira FA et al. (2014). Neuroinflammation as a possible link between cannabinoids and addiction. Acta Neuropsychiatr, 26, 334-46. doi:10.1017/neu.2014.24

94. Correia C, Romieu P, Olmstead MC, Befort K. (2020). Can cocaine-induced neuroinflammation explain maladaptive cocaine-associated memories? Neurosci Biobehav Rev, 111, 69-83. doi:10.1016/j.neubiorev.2020.01.001

95. Kimura H. (2013). Histone modifications for human epigenome analysis. J Hum Genet, 58, 439-45. doi:10.1038/jhg.2013.66

96. Sims RJ, 3rd, Nishioka K, Reinberg D. (2003). Histone lysine methylation: a signature for chromatin function. Trends Genet, 19, 629-39. doi:10.1016/j.tig.2003.09.007

97. Almeida MM, Dias-Rocha CP, Reis-Gomes CF, Wang H, Atella GC, Cordeiro A et al. (2019). Maternal high-fat diet impairs leptin signaling and up-regulates type-1 cannabinoid receptor with sex-specific epigenetic changes in the hypothalamus of newborn rats. Psychoneuroendocrinology, 103, 306-315. doi:10.1016/j.psyneuen.2019.02.004

98. D'Addario C, Zaplatic E, Giunti E, Pucci M, Micioni Di Bonaventura MV, Scherma M et al. (2020). Epigenetic regulation of the cannabinoid receptor CB1 in an activity-based rat model of anorexia nervosa. Int J Eat Disord, 53, 432-446. doi:10.1002/eat.23271 
99. Mancino S, Burokas A, Gutierrez-Cuesta J, Gutierrez-Martos M, Martin-Garcia E, Pucci M et al. (2015). Epigenetic and Proteomic Expression Changes Promoted by Eating Addictive-Like Behavior. Neuropsychopharmacology, 40, 2788-800. doi:10.1038/npp.2015.129

100. Pucci M, Micioni Di Bonaventura MV, Vezzoli V, Zaplatic E, Massimini M, Mai S et al. (2019). Preclinical and Clinical Evidence for a Distinct Regulation of Mu Opioid and Type 1 Cannabinoid Receptor Genes Expression in Obesity. Front Genet, 10, 523. doi:10.3389/fgene.2019.00523

101. D'Addario C, Micale V, Di Bartolomeo M, Stark T, Pucci M, Sulcova A et al. (2017). A preliminary study of endocannabinoid system regulation in psychosis: Distinct alterations of CNR1 promoter DNA methylation in patients with schizophrenia. Schizophr Res, 188, 132140. doi:10.1016/j.schres.2017.01.022

102. Farris SP, Harris RA, Ponomarev I. (2015). Epigenetic modulation of brain gene networks for cocaine and alcohol abuse. Front Neurosci, 9, 176. doi:10.3389/fnins.2015.00176

103. Zhou Z, Yuan Q, Mash DC, Goldman D. (2011). Substance-specific and shared transcription and epigenetic changes in the human hippocampus chronically exposed to cocaine and alcohol. Proc Natl Acad Sci U S A, 108, 6626-31. doi:10.1073/pnas.1018514108

104. Becker JB, Hu M. (2008). Sex differences in drug abuse. Front Neuroendocrinol, 29, 36-47. doi:10.1016/j.yfrne.2007.07.003

105. Kokane SS, Perrotti LI. (2020). Sex Differences and the Role of Estradiol in Mesolimbic Reward Circuits and Vulnerability to Cocaine and Opiate Addiction. Front Behav Neurosci, 14, 74. doi:10.3389/fnbeh.2020.00074

106. Quigley JA, Logsdon MK, Turner CA, Gonzalez IL, Leonardo NB, Becker JB. (2021). Sex differences in vulnerability to addiction. Neuropharmacology, 187, 108491. doi:10.1016/j.neuropharm.2021.108491

107. Quigley JA, Becker JB. (2021). Activation of G-protein coupled estradiol receptor 1 in the dorsolateral striatum attenuates preference for cocaine and saccharin in male but not female rats. Horm Behav, 130, 104949. doi:10.1016/j.yhbeh.2021.104949

108. Hamilton PJ, Nestler EJ. (2019). Epigenetics and addiction. Curr Opin Neurobiol, 59, 128-136. doi:10.1016/j.conb.2019.05.005

109. Fonteneau M, Filliol D, Anglard P, Befort K, Romieu P, Zwiller J. (2017). Inhibition of DNA methyltransferases regulates cocaine self-administration by rats: a genome-wide DNA methylation study. Genes Brain Behav, 16, 313-327. doi:10.1111/gbb.12354

110. Campbell RR, Kramar EA, Pham L, Beardwood JH, Augustynski AS, Lopez AJ et al. (2021). HDAC3 Activity within the Nucleus Accumbens Regulates Cocaine-Induced Plasticity and Behavior in a Cell-Type-Specific Manner. J Neurosci, 41, 2814-2827. doi:10.1523/JNEUROSCI.2829-20.2021

111. Toro CA, Wright H, Aylwin CF, Ojeda SR, Lomniczi A. (2018). Trithorax dependent changes in chromatin landscape at enhancer and promoter regions drive female puberty. Nat Commun, 9, 57. doi:10.1038/s41467-017-02512-1 
A

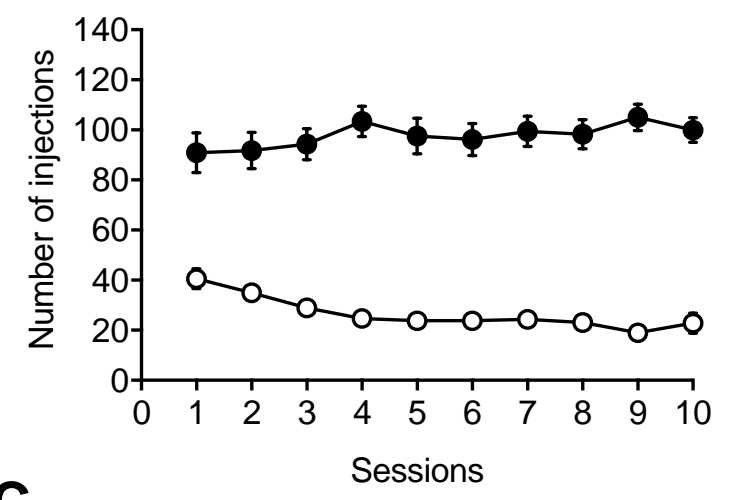

C

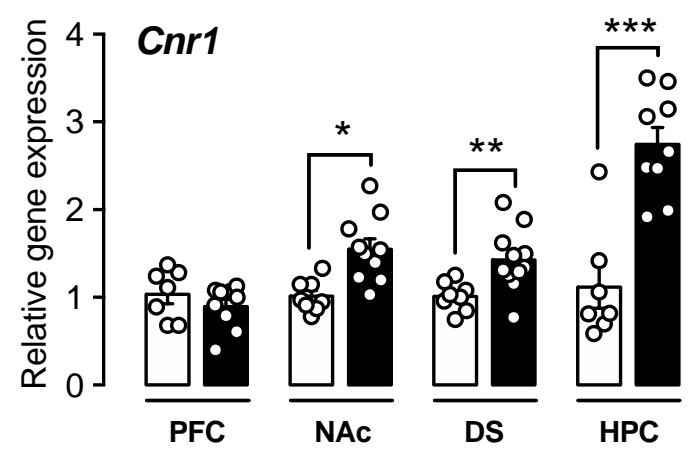

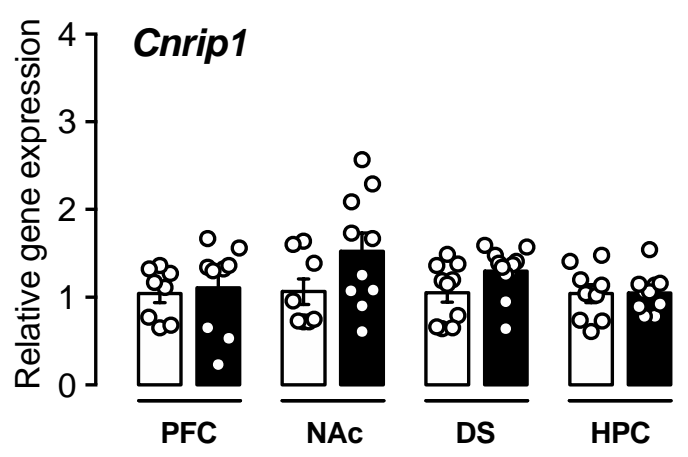

B

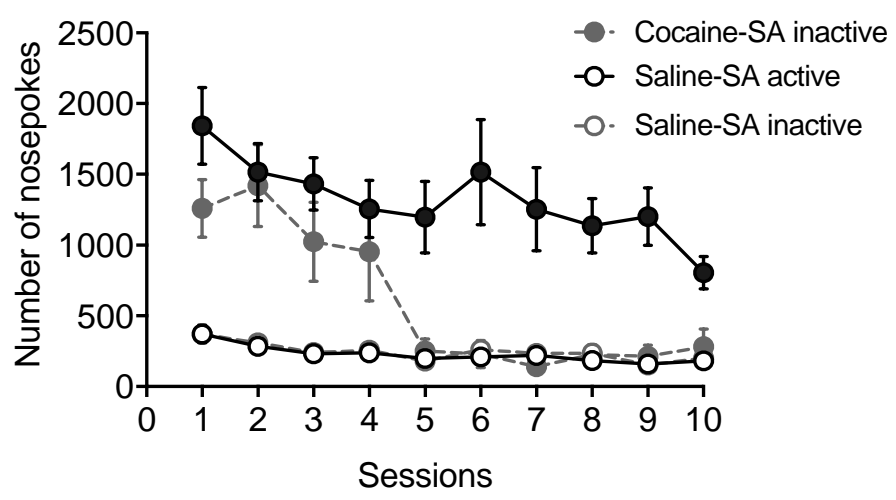

D
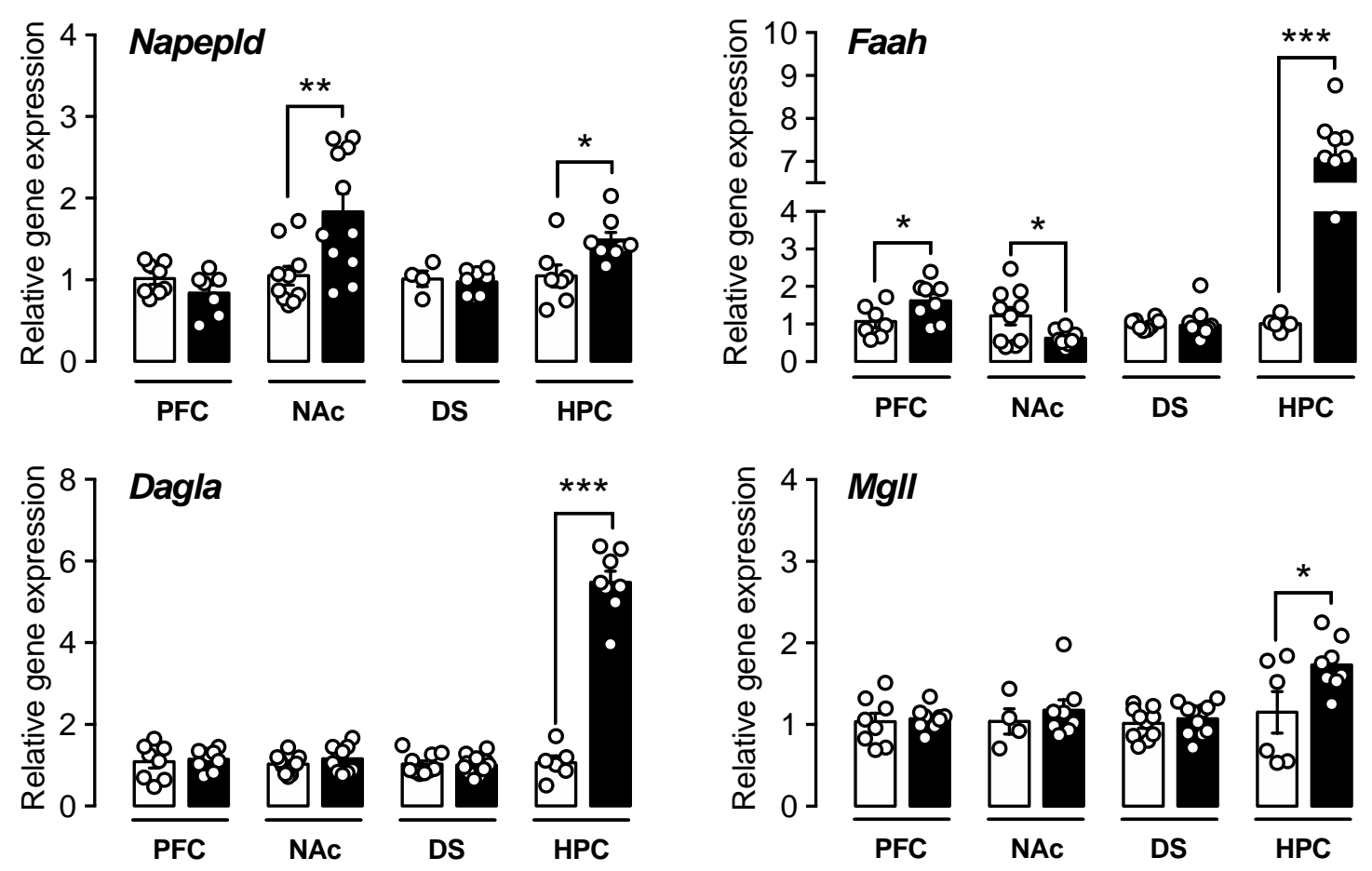

Figure 1 
A

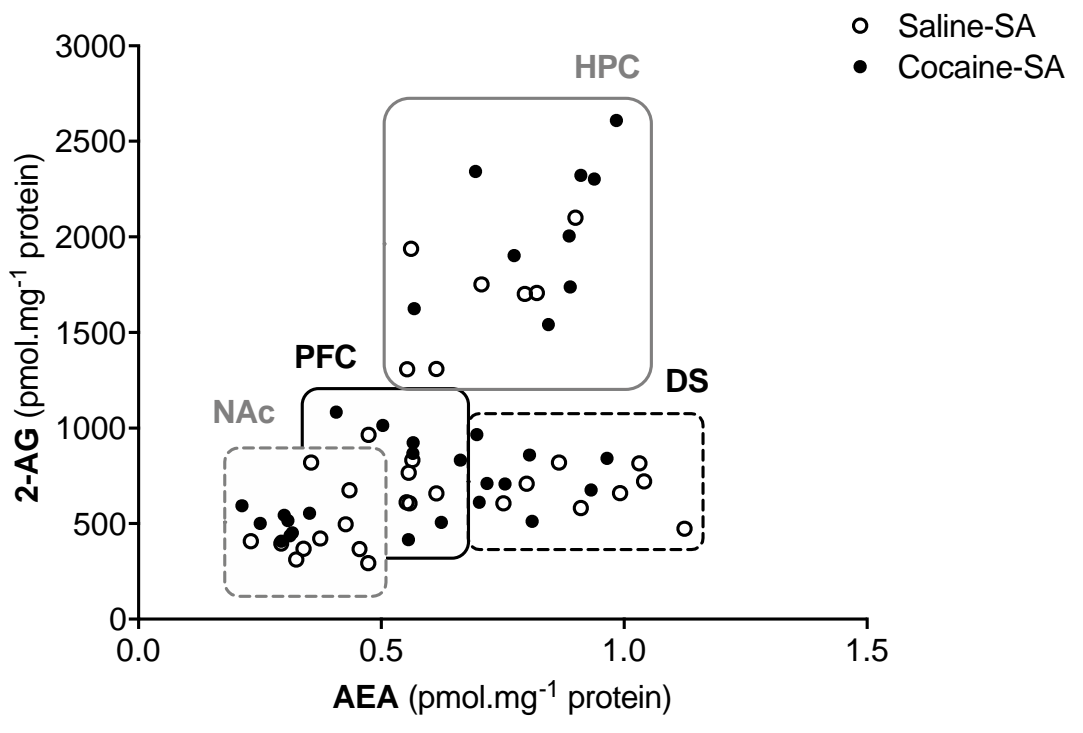

B

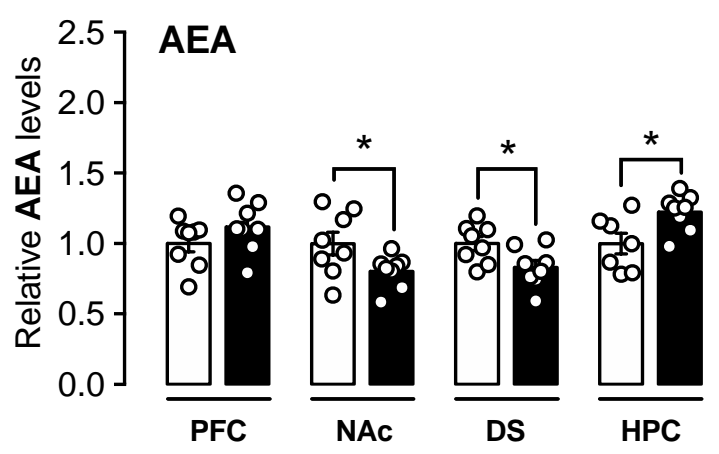

C

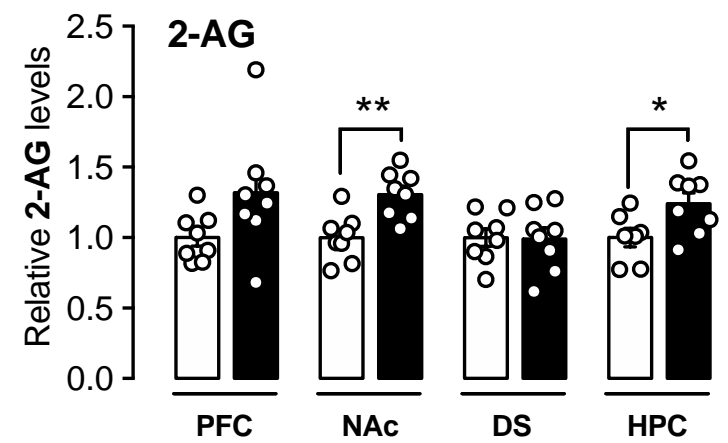


A

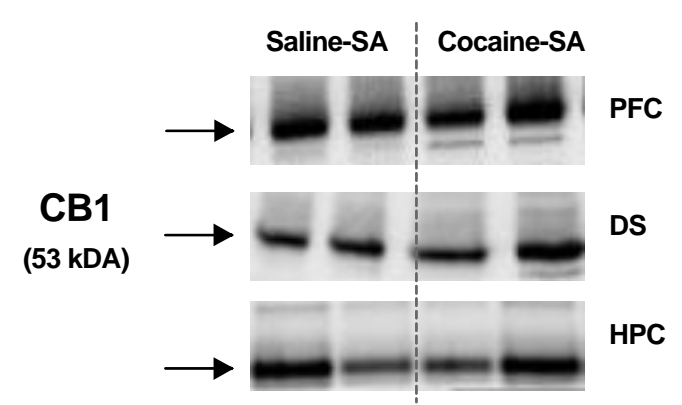

C

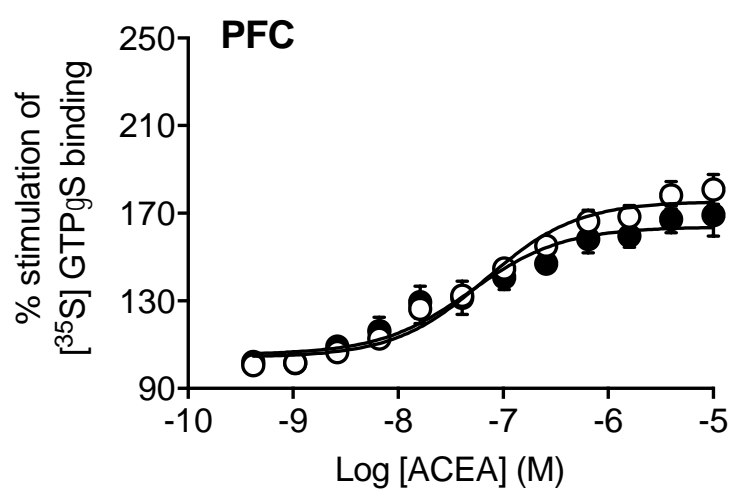

E

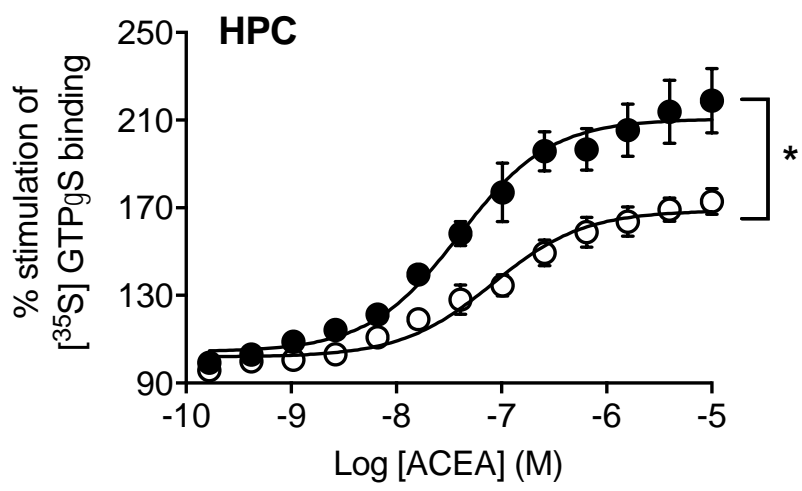

B

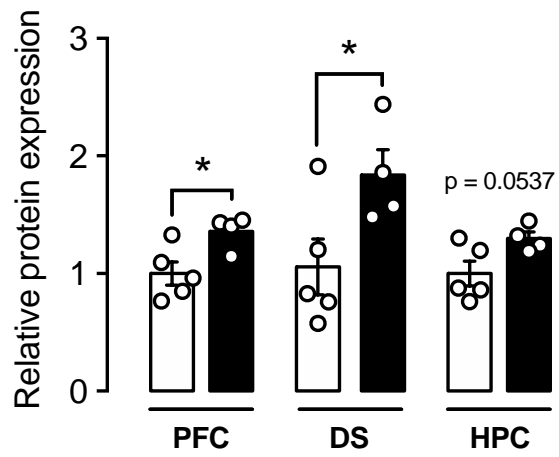

D

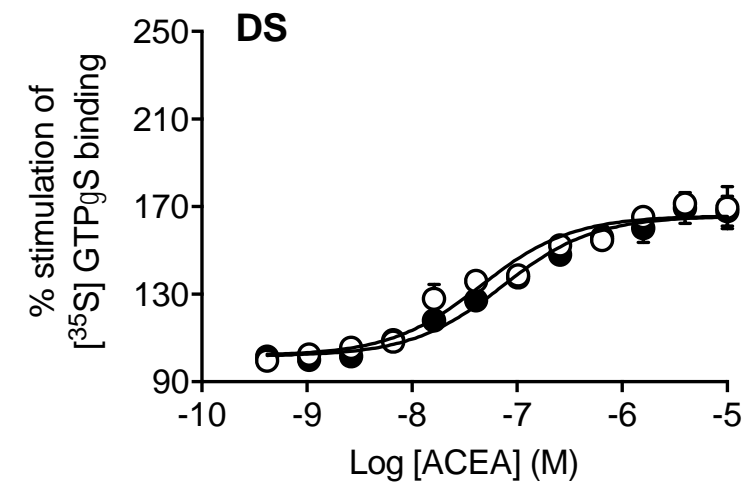


A
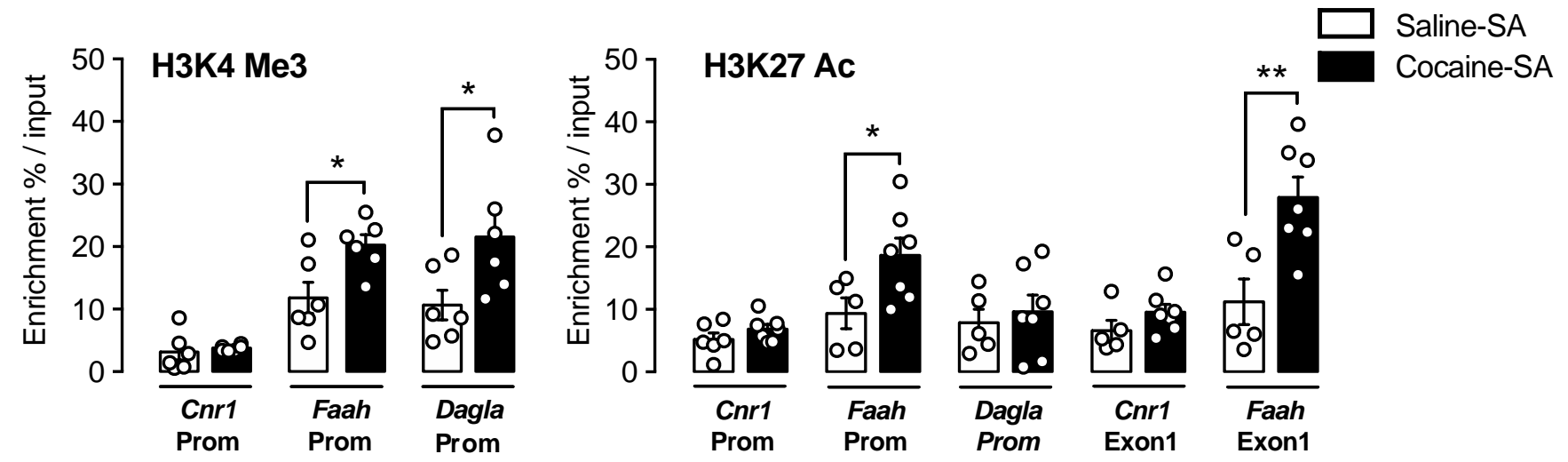

B

-HPC Saline-SA

C
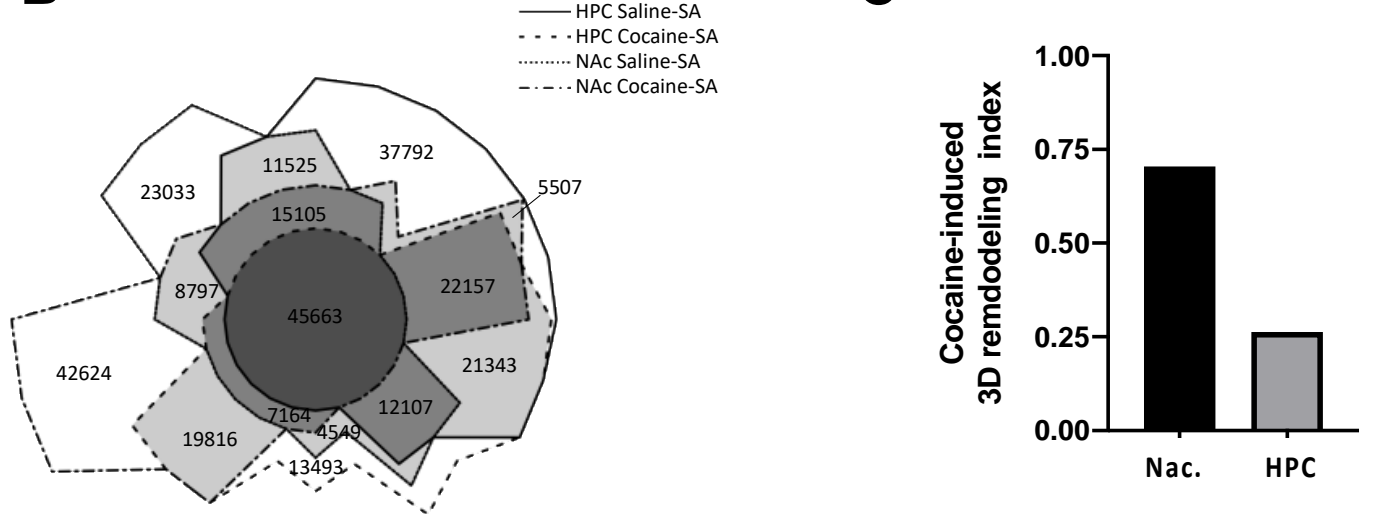